\title{
Insights on the Multifunctional Activities of Magnolol
}

\author{
Jianhong Zhang $\left(\mathbb{D},{ }^{1}\right.$ Zhixi Chen $\left(\mathbb{D},{ }^{2} \text { Xianhua Huang, }{ }^{2} \text { Weimei Shi } \mathbb{D}\right)^{2}$ \\ Rui Zhang $\mathbb{D}^{2}{ }^{2}$ Meiling Chen $\mathbb{D}^{3},{ }^{3}$ Hao Huang $\mathbb{D}^{2}$, and Longhuo $\mathrm{Wu} \mathbb{D}^{2}$ \\ ${ }^{1}$ Department of General Surgery, First Affiliated Hospital of Gannan Medical University, \\ Ganzhou 341000, China \\ ${ }^{2}$ College of Pharmacy, Gannan Medical University, Ganzhou 341000, China \\ ${ }^{3}$ Department of Oncology, Maternity and Child Healthcare Hospital of Jiangxi Province, \\ Nanchang 330006, China \\ Correspondence should be addressed to Hao Huang; hwaohuanghao@gmail.com and Longhuo Wu; longhwu@hotmail.com
}

Received 21 March 2019; Revised 3 May 2019; Accepted 15 May 2019; Published 23 May 2019

Academic Editor: Antoni Camins

Copyright (C) 2019 Jianhong Zhang et al. This is an open access article distributed under the Creative Commons Attribution License, which permits unrestricted use, distribution, and reproduction in any medium, provided the original work is properly cited.

Over years, various biological constituents are isolated from Traditional Chinese Medicine and confirmed to show multifunctional activities. Magnolol, a hydroxylated biphenyl natural compound isolated from Magnolia officinalis, has been extensively documented and shows a range of biological activities. Many signaling pathways include, but are not limited to, NF- $\kappa \mathrm{B} / \mathrm{MAPK}$, Nrf2/HO-1, and PI3K/Akt pathways, which are implicated in the biological functions mediated by magnolol. Thus, magnolol is considered as a promising therapeutic agent for clinic research. However, the low water solubility, the low bioavailability, and the rapid metabolism of magnolol dramatically limit its clinical application. In this review, we will comprehensively discuss the last fiveyear progress of the biological activities of magnolol, including anti-inflammatory, antimicroorganism, antioxidative, anticancer, neuroprotective, cardiovascular protection, metabolism regulation, and ion-mediating activity.

\section{Introduction}

Magnolol (5,5'-diallyl-2,2'-dihydroxybiphenyl) (Figure 1) is a polyphenolic binaphthalene compound and a structural isomer of honokiol. Both magnolol and honokiol are isolated from the stem bark of a traditional Chinese herbal medicine Magnolia officinalis, which has been used for management of nervous disturbance, abdominal distention or disorders, gastrointestinal food stagnancy, and coughing and dyspnea [1]. Magnolol has showed a wide spectrum of beneficial activities, including anti-inflammation [2, 3], antimicroorganism $[4,5]$, antioxidation $[6,7]$, antiangiogenesis $[8,9]$, anticancer [10-12], neuroprotection $[13,14]$, cardiovascular protection $[15,16]$, and lipolysis activities $[17,18]$. However, there are still some differences between magnolol and honokiol in safety and toxicology, which have been reviewed by Sarrica et al. (2018)[19]. In this review article, the biological activities of magnolol will be discussed comprehensively.

\section{Metabolism and Pharmacokinetic Features of Magnolol}

Cytochrome P450 monooxygenase (CYP) is the typical drug-metabolizing enzyme (phase I metabolism). The ability of magnolol to interact with drugs has been determined by investigating its effects on CYP enzymes. Magnolol is reported to inhibit the activity of CYP1A with an $\mathrm{IC}_{50}$ value of $1.62 \mu \mathrm{M}$, of $\mathrm{CYP} 2 \mathrm{C}$ with an $\mathrm{IC}_{50}$ value of 5.56 $\mu \mathrm{M}$, and of CYP3A with an $\mathrm{IC}_{50}$ value of $35.0 \mu \mathrm{M}$. Dixon plot research in rat liver microsomes (RLM) shows that magnolol inhibits CYP1A with $K_{i}$ value of 1.09-12.0 $\mu \mathrm{M}$ in uncompetitive-dependent manner and CYP2C and CYP3A with $K_{i}$ values of 10.0-15.2 $\mu \mathrm{M}$ and 93.7-183 $\mu \mathrm{M}$, respectively, in competitive-dependent manner [20]. In contrast, magnolol inhibits CYP2C enzyme-catalyzed hydroxylation with $\mathrm{IC}_{50}$ value of $41.48 \mu \mathrm{M}, \mathrm{CYP} 2 \mathrm{D} 6$ with $\mathrm{IC}_{50}$ value of $65.42 \mu \mathrm{M}$, CYP2E1 with $\mathrm{IC}_{50}$ value of $67.93 \mu \mathrm{M}$, CYP3A4 

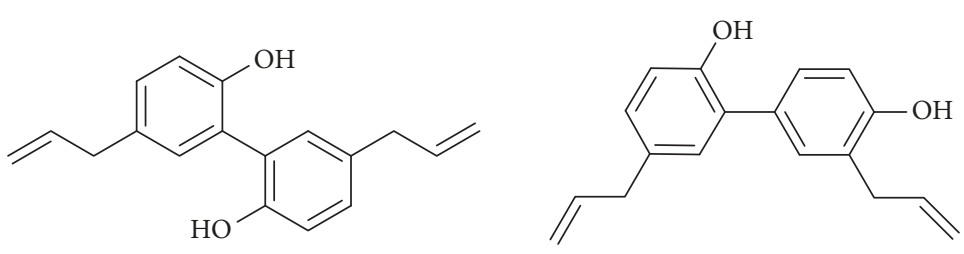

FIGURE 1: The chemical structures of magnolol (left) and honokiol (right).

with $\mathrm{IC}_{50}$ value of $52.36 \mu \mathrm{M}$, and CYP2B6 with $\mathrm{IC}_{50}$ value of $28.68 \mu \mathrm{M}$ [21]. This suggests that magnolol might potentially interact with coadministrated drugs metabolized by CYP enzymes pharmacologically. The direct effects of magnolol on hepatic CYP1A and CYP2C-mediated metabolism have been investigated and found that magnolol inhibits CYP1A (phenacetin as the substrate, $\mathrm{IC}_{50}$ value of $19.0 \mu \mathrm{M}$ ) more potently than CYP2C (diclofenac as the substrate, $\mathrm{IC}_{50}$ value of $47.3 \mu \mathrm{M}$ ) [22] (Table 2).

The value of mean peak plasma concentration of magnolol reaches $426.4 \pm 273.8 \mathrm{ng} / \mathrm{mL}$ after oral administration, and the bioavailability of magnolol reaches $17.5 \pm 9.7 \%$ [23]. However, the absolute bioavailability of magnolol is only $4 \%$. Magnolol is predominantly distributed in liver, kidney, brain, lung, and heart. And the liver contains the highest contents of magnolol and magnolol-glucuronides [24]. In addition, two main metabolites, isomagnolol and tetrahydromagnolol, have been identified and predicted to exhibit a potential synergistic effect with magnolol or other molecules acting on cannabinoid (CB) receptors [25]. The metabolites of magnolol increase dramatically after repeated doses, indicating that they are implicated in the induction of metabolic enzymes [26].

Magnolol is often available for human in daily life because it is the major component of extract, which adds to mints and gums. It has been estimated that the safe dose of magnolol available for teenage is up to $1.64 \mathrm{mg} / \mathrm{kg}$ per day. The extensive research indicates that magnolol undergoes glucuronidation (phase II metabolism) before its elimination in human and rats, as indicated by transferring glucuronic acid from UDP-glucuronic acid to magnolol and making it more soluble and excreted by the kidney [27]. Such glucuronidation involves several UDP-glucuronosyltransferase (UGTs) isoforms, including UGT1A1, UGT1A3, UGT1A7, UGT1A8, UGT1A9, UGT1A10, and UGT2B7. Of which UGT2B7 is the major enzyme responsible for magnolol glucuronidation in human liver microsomes (HLM). In addition, UGT1A10 and UGT2B7 are the two major contributors in human intestine microsomes (HIM) [1]. Glucuronides of $\beta$-estradiol or SN-38 generated in microsomal or HeLalAl cell incubations have been quantified, and magnolol shows inhibitory effects $(\beta$ estradiol: $\mathrm{IC}_{50}$ value of $36.8 \mu \mathrm{M}$ and $22.6 \mu \mathrm{M}$, respectively; SN-38: $\mathrm{IC}_{50}$ value of $13.2 \mu \mathrm{M}$ and $16.4 \mu \mathrm{M}$, respectively) [28] (Table 2). In addition, UGT1A7 and UGT1A9 have been selectively inhibited on 4-methylumbelliferone (4-Mu) by magnolol with $\mathrm{Ki}$ values of $0.487 \mu \mathrm{M}$ and $0.048 \mu \mathrm{M}$, respectively [29]. Thus, magnolol is considered as an atypical substrate of UGT. This indicates that magnolol can show competitive activity with other drugs for interacting with
UGT. It has been demonstrated that magnolol in human can inhibit the glucuronidation of propofol, which has considered the biomarker of UGT1A9 reaction. Thus, magnolol has been proposed to prolong the anesthesia time. However, it has been found that magnolol-mediated inhibition of propofol glucuronidation varies among species dramatically, including Bama pigs, cynomolgus macaques, mice, and rats [30].

Due to the low water solubility and quick metabolism, magnolol has a low bioavailability and limits its applications in clinical development. The mixed micelles containing pluronic F127 and L61 for delivering magnolol might be a well strategy for resolving its problem of poor solubility and bioavailability [31]. Similarly, solid dispersion of magnolol with polyvinylpyrrolidone K-30 (PVP) has been shown to increase water solubility of magnolol from 12 to $105 \mu \mathrm{g} / \mathrm{mL}$, when PVP concentration increases from 0 to $100 \mu \mathrm{M}$. The pharmacokinetic parameters indicate that the $\mathrm{AUC}_{0-t}$ and $C_{\max }$ of magnolol in solid dispersion with PVP are $80.1 \%$ and $44.7 \%$. Additionally, the $\mathrm{AUC}_{0-t}$ and $\mathrm{C}_{\max }$ of magnolol sulfates or glucuronides are $142.8 \%$ and $126.4 \%$, respectively, compared to magnolol pure compound [32]. Furthermore, magnolol-loaded microparticles with size value of $3.73 \pm 0.41 \mu \mathrm{M}$ prepared by single emulsion method from a polyketal polymer have exhibited good biocompatibility and approached macrophage-mediated phagocytosis and pulmonary drug delivery [33].

\section{Anti-Inflammatory Activity}

Peroxisome proliferator-activated receptor $\gamma(\operatorname{PPAR} \gamma)$ has been demonstrated to be capable of ameliorating lipopolysaccharide (LPS)-induced inflammatory activity to suppress the activation of nuclear factor- $\kappa \mathrm{B}(\mathrm{NF}-\kappa \mathrm{B})$ signaling and the expression of its downstream proinflammatory cytokines in airway epithelial cells and neutrophilia [2]. Magnolol has been investigated for protecting acute lung injury (ALI) and proved to greatly upregulate the expression of PPAR $\gamma$ and suppress the expression of NF- $\kappa \mathrm{B}$ signaling, cyclooxygenase2 (COX-2), and inducible nitric oxide synthase (iNOS) and the production of ROS in bronchoalveolar lavage fluid, resulting in improvement of lung edema and polymorphonuclear neutrophil infiltration [34] (Table 1). Lung inflammation plays a critical role in development of asthma and COPD (chronic obstructive pulmonary disease). Magnolol has been demonstrated to inhibit the increased expression of intercellular adhesion molecule 1 (ICAM-1) induced by tumor necrosis factor $\alpha(\mathrm{TNF} \alpha)$ in A549 cells through suppression of $\mathrm{NF}-\kappa \mathrm{B} /$ mitogen-activated protein kinase (MAPK) signaling pathway, as evidenced by downregulation of phosphorylation 
TABLE 1: The multifunctional activities of magnolol.

\begin{tabular}{|c|c|c|c|c|}
\hline Category & Models & Doses & Biological activities & Ref. \\
\hline \multirow{5}{*}{$\begin{array}{l}\text { Anti- } \\
\text { inflammation }\end{array}$} & UC mice & $\begin{array}{l}25,50, \text { and } 100 \\
\mathrm{mg} / \mathrm{kg}\end{array}$ & $\begin{array}{c}\mathrm{TNF} \alpha \downarrow, \mathrm{IL}-1 \beta \downarrow, \mathrm{IL}-12 \downarrow, \operatorname{PPAR} \gamma \uparrow, \mathrm{NF}-\kappa \mathrm{B} \downarrow, \mathrm{ZO}-1 \uparrow, \\
\text { occludin } \uparrow\end{array}$ & {$[3]$} \\
\hline & LPS-induced ALI rats & 10 and $20 \mathrm{mg} / \mathrm{kg}$ & $\begin{array}{c}\operatorname{PPAR} \gamma \uparrow, \mathrm{NF}-\kappa \mathrm{B} \downarrow, \mathrm{COX}-2 \downarrow \text {, iNOS } \downarrow \text {, ROS } \downarrow \text {, lung } \\
\text { edema } \downarrow\end{array}$ & {$[34]$} \\
\hline & A549 & $\begin{array}{l}20 \text { and } 50 \\
\mu \mathrm{mol} / \mathrm{L}\end{array}$ & ICAM- $1 \downarrow$, NF- $\kappa \mathrm{B} \downarrow, \mathrm{p} 38 \downarrow, \mathrm{ERK} 1 / 2 \downarrow, \mathrm{SAPK} / \mathrm{JNK} \downarrow$ & {$[35]$} \\
\hline & LPS-induced MUECs & $\begin{array}{l}12.5,25 \\
50 \mu \mathrm{g} / \mathrm{mL}\end{array}$ & $\begin{array}{c}\mathrm{TNF} \alpha \downarrow, \mathrm{IL}-6 \downarrow, \mathrm{p}-\mathrm{ERK} \downarrow, \mathrm{p}-\mathrm{JNK} \downarrow, \mathrm{p}-\mathrm{p} 38 \downarrow, \mathrm{NF}-\kappa \mathrm{B} \downarrow \\
\text { MAPK } \downarrow\end{array}$ & {$[38]$} \\
\hline & LPS-induced MMECs & $\begin{array}{l}12.5,25 \\
50 \mu \mathrm{g} / \mathrm{mL}\end{array}$ & 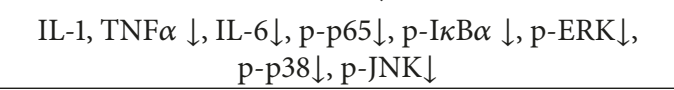 & [39] \\
\hline \multirow{3}{*}{$\begin{array}{l}\text { Anti- } \\
\text { microorganism }\end{array}$} & LPS-induced RAW 264.7 & 5,10, and $20 \mu \mathrm{M}$ & $\begin{array}{c}\mathrm{Nrf}-2 / \mathrm{HO}-1 \uparrow, \mathrm{NF}-\kappa \mathrm{B} \downarrow, \mathrm{iNO} \downarrow \\
\mathrm{NO} \downarrow\end{array}$ & {$[4]$} \\
\hline & MT8148 & $\begin{array}{l}10,20, \text { and } \\
50 \mu \mathrm{g} / \mathrm{mL}\end{array}$ & $\begin{array}{c}\text { Good penetration and bactericidal activity on } \\
\text { MT8148 biofilm }\end{array}$ & {$[43]$} \\
\hline & Channel catfish & $\begin{array}{l}2,4,8, \text { and } \\
16 \mu \mathrm{g} / \mathrm{mL}\end{array}$ & $\begin{array}{l}\text { Inhibit hemolytic activity of supernatants from } A \text {. } \\
\text { hydrophila culture }\end{array}$ & {$[44]$} \\
\hline \multirow{3}{*}{ Anti-oxidation } & SAM & 10 and $30 \mathrm{mg} / \mathrm{kg}$ & $\begin{array}{c}4-\mathrm{HNE} \downarrow, \text { iNOS } \downarrow \text {, p-p38 MAPK } \downarrow \text {, IL- } 1 \beta, \text { TNF } \alpha \downarrow \text {, } \\
\text { IL- } \downarrow \downarrow\end{array}$ & {$[6]$} \\
\hline & 3T3-L1 & 5,10, and $20 \mu \mathrm{M}$ & $\begin{array}{c}\text { ROS } \downarrow \text {, FAS } \downarrow, \text { SREBP } 1 \downarrow, \mathrm{UCP} 1 \uparrow, \mathrm{Cd} 137 \uparrow, \operatorname{Prdm} 16 \uparrow, \\
\text { Cidea } \uparrow, \mathrm{Tbx} 1 \uparrow, \mathrm{PGC}-1 \alpha \uparrow, \mathrm{CPT} 1 \uparrow, \mathrm{ACSL} 1 \uparrow, \mathrm{SIRT} 1 \uparrow, \\
\mathrm{PLIN} \uparrow\end{array}$ & {$[7]$} \\
\hline & SH-5Y5Y & 8,16, and $32 \mu \mathrm{M}$ & $\begin{array}{l}\text { ROS } \downarrow \text {, JNK/mitochondrial caspases } \downarrow \text {, } \\
\text { PI3K/MEK/ERK } \downarrow \text {, PI3K/Akt/FOXO1 } \downarrow\end{array}$ & {$[49]$} \\
\hline \multirow{6}{*}{ Anti-cancer } & U87MG and LN229 & 20 and $40 \mu \mathrm{M}$ & $\begin{array}{l}\text { Cyclin A } \downarrow \text {, cyclin D1 } \downarrow, \text { CDK } 2 \downarrow, \text { CDK } 4 \downarrow, \text { CDK6 } \downarrow \text {, } \\
\text { p-PI3K } \downarrow \text {, p-Akt } \downarrow \text {, p-p38 } \downarrow \text {, p-JNK } \downarrow, \text { Ki67 } \downarrow \text {, p-ERK } \uparrow\end{array}$ & {$[11]$} \\
\hline & U373 & $\begin{array}{l}10,20 \text {, and } \\
40 \mu \mathrm{M}\end{array}$ & $\begin{array}{c}\text { Arrest at } \mathrm{G}_{0} / \mathrm{G}_{1} \text { phase, cyclin } \mathrm{D} 1 \downarrow \text {, cyclin } \mathrm{A} \downarrow \text {, } \\
\text { CDK2 } 2 \text {, p21/Cip1 } \uparrow\end{array}$ & {$[50]$} \\
\hline & $\mathrm{U} 373$ & $100 \mu \mathrm{M}$ & $\begin{array}{l}\mathrm{p} 27 / \mathrm{Kip} 1 \uparrow, \uparrow \text { phosphorylation of cSrc, ERK, p38, and } \\
\text { Akt. }\end{array}$ & {$[51]$} \\
\hline & CCA & 20 and $40 \mu \mathrm{M}$ & $\begin{array}{l}\text { Ki67 } \downarrow, \text { PCNA } \downarrow, \text { MMP- } 2 \downarrow, \text { MMP-7 } \downarrow \text {, MMP-9 } \downarrow \text {, } \\
\text { CyclinD1 } \downarrow, \text { p-I } \kappa \text { B } \alpha \downarrow \text {, p-p65 } \downarrow\end{array}$ & {$[52]$} \\
\hline & Mice bladder cancer & $10 \mathrm{mg} / \mathrm{kg} / \mathrm{d}$ & $\begin{array}{c}\text { Myostatin } \downarrow \text {, activin } \mathrm{A} \downarrow \text {, p-Akt } \uparrow, \mathrm{p}-\mathrm{FOXO} 3 \uparrow, \mathrm{IGF}-1 \uparrow \\
\mathrm{p}-\mathrm{mTOR} \uparrow, \mathrm{p}-\mathrm{p} 70 \mathrm{~S} 6 \mathrm{~K} \uparrow, \mathrm{p}-4 \mathrm{EBP}-1 \uparrow\end{array}$ & {$[53]$} \\
\hline & HUVECs & $0.1,0.5$, and $1 \mu \mathrm{M}$ & $\begin{array}{c}\text { Inhibit VEGF-stimulated proliferation, chemotactic } \\
\text { motility, tube formation, and vessel sprouting, } \\
\text { MEK/ERK } \downarrow \text {, PI3K/Akt } \downarrow\end{array}$ & {$[54]$} \\
\hline \multirow{3}{*}{ Neuroprotection } & Scop-induced mice & $\begin{array}{l}15,25 \text {, and } 35 \\
\mathrm{mg} / \mathrm{kg}\end{array}$ & AChE $\uparrow$, total SOD $\uparrow, \mathrm{NOS} \uparrow, \mathrm{MDA} \uparrow$ & {$[55]$} \\
\hline & CORT-induced rats & $\begin{array}{l}50 \text { and } 100 \\
\mathrm{mg} / \mathrm{kg}\end{array}$ & FST $\uparrow$, TST $\uparrow, \mathrm{BDNF} \uparrow, 5-\mathrm{HT} \uparrow, \mathrm{NE} \uparrow$ & {$[56]$} \\
\hline & I/R mice & $\begin{array}{l}1.4,7.0, \text { and } 35 \\
\mu \mathrm{g} / \mathrm{kg}\end{array}$ & $\begin{array}{l}\text { Decrease cerebral infarct volume, brain water } \\
\text { content, and the exudation of Evans blue }\end{array}$ & {$[57]$} \\
\hline \multirow{3}{*}{$\begin{array}{l}\text { Cardiovascular } \\
\text { protection }\end{array}$} & SHR and HUVECs & $\begin{array}{c}100 \mathrm{mg} / \mathrm{kg} / \mathrm{d} \text { and } \\
10 \mu \mathrm{M}\end{array}$ & $\begin{array}{c}\text { Restore insulin-mediated Akt, eNOS, and aorta } \\
\text { vasolidation, PPAR } \gamma \uparrow, \text { TRB3 } \downarrow\end{array}$ & {$[15]$} \\
\hline & VSMCs & $\begin{array}{c}5,10,20, \text { and } \\
30 \mu \mathrm{M}\end{array}$ & $\begin{array}{l}\text { Arrest at } \mathrm{G}_{0} / \mathrm{G}_{1}, \text { cyclinD } 1 \downarrow, \text { cyclinE } \downarrow, \mathrm{CDK} 2 \downarrow \text {, } \\
\qquad \mathrm{CDK} 4 \downarrow, \mathrm{p}-\mathrm{ERK} 1 / 2 \downarrow, \mathrm{NF}-\kappa \mathrm{B} \downarrow\end{array}$ & {$[16]$} \\
\hline & HAECs & $5 \mu \mathrm{M}$ & $\begin{array}{c}\mathrm{JNK} / \mathrm{p} 38 \text { phosphorylation } \downarrow \text {, HuR translocation } \downarrow \text {, } \\
\text { NF- } \kappa \mathrm{B} \downarrow \text {, VCAM- } 1 \downarrow\end{array}$ & {$[58]$} \\
\hline \multirow{2}{*}{$\begin{array}{l}\text { Metabolism } \\
\text { regulation }\end{array}$} & RAW 264.7 & $\begin{array}{l}20,40, \text { and } \\
60 \mu \mathrm{M}\end{array}$ & ADRP $\downarrow$, lipolysis $\downarrow$ & {$[17]$} \\
\hline & 3T3-L1 & 1 and $10 \mu \mathrm{M}$ & $\begin{array}{l}\text { Enhances adipocytes differentiation and glucose } \\
\text { uptake }\end{array}$ & {$[59]$} \\
\hline
\end{tabular}


TABLE 2: The inhibitory effects of magnolol on different targets.

\begin{tabular}{|c|c|c|c|c|c|}
\hline Substrate & Enzyme (target) source & $\mathrm{IC}_{50}(\mu \mathrm{M})$ & $K i(\mu \mathrm{M})$ & $\mathrm{EC}_{50}(\mu \mathrm{M})$ & Ref. \\
\hline $\mathrm{NF}$ & CYP1A & 1.62 & $1.09-12.0$ & - & \multirow{3}{*}[20]{} \\
\hline SPZ & CYP2C & 0.56 & $10.0-15.2$ & - & \\
\hline $\mathrm{KCZ}$ & CYP3A & 35 & $93.7-183$ & - & \\
\hline meropenem & NDM-1 & $6.47(\mu \mathrm{g} / \mathrm{mL})$ & - & - & {$[60]$} \\
\hline- & Porphyromonas gingivalis, Aggregatibacter actinomycetemcomitans & 100 & - & - & [61] \\
\hline CP55,940 & $\mathrm{CB} 2$ & - & 1.44 & 3.28 & {$[25]$} \\
\hline pNP- $\alpha-G$ & $\alpha$-Glucosidase & 2.0 & - & - & {$[62]$} \\
\hline 4-hydroxy tolbutamide & CYP2C & 41.48 & \multirow{5}{*}{-} & \multirow{5}{*}{-} & \multirow{5}{*}[21]{} \\
\hline dextrorphan & CYP2D6 & 65.42 & & & \\
\hline 6-hydroxy chlorzoxazone & CYP2E1 & 67.93 & & & \\
\hline 6-hydroxy testosterone & CYP3A4 & 52.36 & & & \\
\hline hydroxybupropion & CYP2B6 & 28.69 & & & \\
\hline p-NPP & PTP1B & 24.6 & - & - & [63] \\
\hline- & $\operatorname{PPAR} \gamma$ (agonist) & - & 2.04 & 1.6 & {$[64]$} \\
\hline$\beta$-Estradiol & UGT1A1 & 36.8 & - & - & \multirow{4}{*}[28]{} \\
\hline$\beta$-Estradiol & Hela1A1 & 22.6 & - & - & \\
\hline SN-38 & UGT1A1 & 13.2 & - & - & \\
\hline$\underline{\mathrm{SN}-38}$ & Hela1A1 & 16.4 & - & - & \\
\hline $4-\mathrm{Mu}$ & UGT1A7 & - & 0.487 & - & \multirow{2}{*}[29]{} \\
\hline $4-\mathrm{Mu}$ & UGT1A9 & - & 0.048 & - & \\
\hline
\end{tabular}

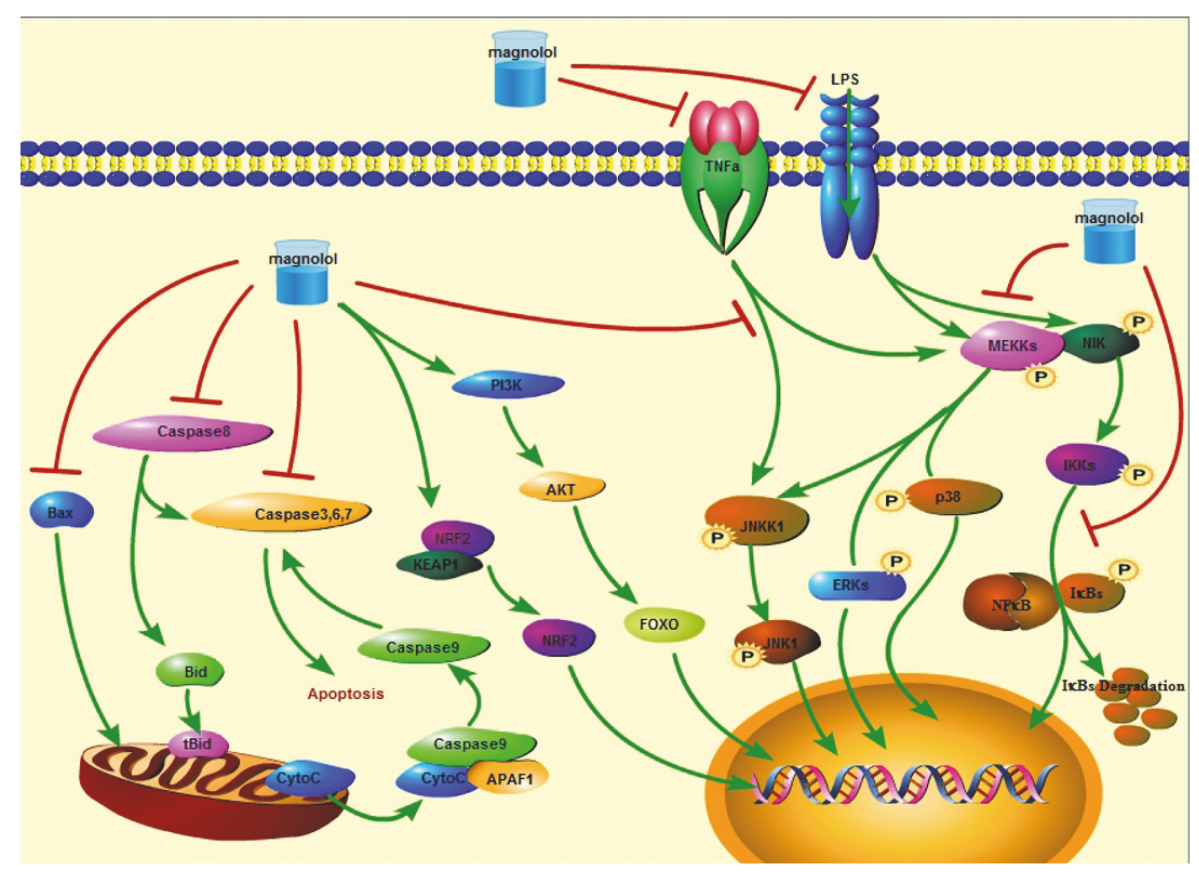

FIGURE 2: Magnolol inhibits NF- $\kappa$ B and MAPK signaling pathways and apoptosis and activates NRF2/KEAP1 and PI3K/Akt/FOXO signaling pathways. Stimulators, such as LPS and TNF $\alpha$, induce activation of NF- $\kappa$ B and MAPK signaling pathways. Magnolol shows inhibitory effects on NF- $\kappa$ B and MAPK signaling pathways, inhibits mitochondrial apoptosis, but upregulates the activities of NRF2/KEAP1 and $\mathrm{PI} 3 \mathrm{~K} / \mathrm{Akt} / \mathrm{FOXO}$ signaling pathways.

of NF- $\kappa \mathrm{B}, \mathrm{p} 38$, extracellular regulated protein kinases $1 / 2$ (ERK1/2), and stress-activated protein kinase (SAPK)/ c-Jun N-terminal kinase (JNK) [35] (Figure 2).

Consistently, magnolol attenuates the expression of TNF $\alpha$, Interleukin $1 \beta$ (IL-1 $\beta$ ), and IL-12 induced by dextran sulphate sodium (DSS) through downregulation of NF- $\kappa \mathrm{B}$ and upregulation of PPAR $\gamma$ expression in ulcerative colitis (UC) mice. In addition, magnolol significantly upregulates the expression of ZO-1 and occludin in DSS-induced UC mice [3]. Tryptophan metabolism greatly contributes to the 
pathogenesis and therapeutics of inflammatory bowel disease (IBD). Magnolol exhibits protective activity against DSSinduced UC mice with the possible molecular mechanism that involves augment of aryl hydrocarbon receptor (AHR) activation through enhancement of tryptophan metabolites production, which significantly suppresses the colonic inflammation [36]. In 2,4,6-trinitrobenzene sulfonic acid (TNBS)-induced rats colitis, magnolol reduces the activity of colonic myeloperoxidase, the levels of proinflammatory cytokines, and the mRNA expression of toll-like receptor 4 (TLR4). These might be associated with attenuation of NF$\kappa \mathrm{B}$ signaling [37].

In LPS-induced mice uterine epithelial cells (MUECs), magnolol significantly suppresses the expression of TNF $\alpha$, IL-6, p-ERK, p-JNK, and p-p38. These might be associated with inhibition of TLR4-regulated NF- $\kappa \mathrm{B}$ signaling and MAPK signaling [38] (Table 1). Similarly, it has been demonstrated that magnolol significantly ameliorates the activity of LPS-induced IL- $1 \beta$, TNF $\alpha$, and IL- 6 in vivo and in vitro. In addition, magnolol also decreases the expression of $\mathrm{p}$-p65, $\mathrm{p}-\mathrm{I} \kappa \mathrm{B} \alpha, \mathrm{p}-\mathrm{ERK}, \mathrm{p}-\mathrm{p} 38$, and $\mathrm{p}-\mathrm{JNK}$ in LPS-triggered mouse mammary epithelial cells (MMECs) through suppression of TLR4/NF- $\kappa \mathrm{B} / \mathrm{MAPK}$ signaling pathway [39] (Figure 2). LPS-induced inflammatory and oxidative stresses have been shown to be related to sepsis-triggered dysmotility. Magnolol can significantly accelerate intestinal transit, improve circular muscle contraction, and ameliorate the morphology changes of interstitial cells of Cajal (ICCs) in male gerbils stimulated by LPS. The possible molecular mechanism might be related to the protective activity of magnolol against sepsisinduced decreased expression of SCF/p-c-kit and superoxide dismutase (SOD) and increased expression of iNOS/NO and malondialdehyde (MDA) [40].

In renal $\mathrm{I} / \mathrm{R}$ injury, magnolol has been found to inhibit the increased expression of TNF $\alpha$, IL- $1 \beta$, IL- 6 , Bax, and the proapoptotic MAPK (p38 and JNK) phosphorylation and enhance the decreased expression of IL-10, Bcl-2, and the prosurvival Akt and ERK1/2 phosphorylation, resulting in inhibition of apoptosis extrinsically and intrinsically [41]. CB receptors, belonging to the G-protein coupled receptor family, have two subtypes CB1 and CB2. CB2 activation is linked to analgesic and anti-inflammatory activities. Magnolol acts as a partial agonist for $\mathrm{CB} 2$ selectively with $\mathrm{EC}_{50}$ value of 3.28 $\mu \mathrm{M}$ [25]. Accordingly, magnolol has been demonstrated to be a ligand for $\mathrm{CB} 2$ receptor docking at the binding site with $\mathrm{EC}_{50}$ value of 1-3 $\mu \mathrm{M}[42]$.

\section{Antimicroorganism Activity}

The release of LPS from Porphyromonas gingivalis has been involved in the inflammation-induced periodontitis development. In LPS-triggered RAW 264.7 macrophages, magnolol abrogates the inflammatory responses, as evidenced by downregulation of NF- $\kappa \mathrm{B}$ signaling, activation of NF-E2related factor 2 (Nrf-2)/heme oxygenase-1 (HO-1) signaling, and suppression of iNOS, COX-2, Prostaglandin E2 ( $\left.\mathrm{PGE}_{2}\right)$, and NO expression. In addition, administration of p38 MAPK and reactive oxygen species (ROS) activators may reverse the effects of magnolol [4] (Table 1). Streptococcus mutans (MT8148), known as a cariogenic bacterium, has been reported to induce a low $\mathrm{pH}$ environment and form a biofilm. Magnolol has been demonstrated to exert bactericidal activity and prevent and manage dental caries by penetrating biofilm and sterilizing S. mutans dose-dependently. In addition, magnolol shows a very low toxicity for gingival epithelial cells at tested concentrations, compared to chlorhexidine (CHX) [43].

Propionibacterium acnes and Propionibacterium granulosum are the two major bacteria responsible for acne. Magnolol and honokiol have been demonstrated to inhibit significantly both of them with the minimum inhibitory concentrations (MIC) values of $9 \mu \mathrm{g} / \mathrm{mL}$ and 3-4 $\mu \mathrm{g} / \mathrm{mL}$, respectively, by employing the disk diffusion method and a twofold serial dilution assay. Furthermore, both magnolol and honokiol do not produce any side effects in human skin primary irritation test [5]. Aeromonas hydrophila contributes to pathogenic infections to human and animals through releasing a poreforming toxin aerolysin, which has become the potential target for drug discovery. Magnolol has been shown to inhibit the hemolytic activity of supernatants from A. hydrophila culture through suppression of aerolysin encoding gene aer $A$ transcription [44] (Table 1).

Grass carp (Ctenopharyngodon idella) often suffers from hemorrhagic disease induced by grass carp reovirus (GCRV). Magnolol has been shown to suppress GCRV replication in CIK cells probably through induction of interferon regulatory factor (IRF)7 and type I IFN (IFN-I) expression. Magnolol significantly promotes IL- $1 \beta$ expression but fails to activate NF- $\kappa \mathrm{B}$ signaling pathway in GCRV-infected CIK cells [45]. Furthermore, magnolol can effectively improve the resisting ability of grass carp against GCRV and attenuate GCRVinduced cell apoptosis through decreasing the activity of caspase-3, -8 , and -9 [46].

\section{Antioxidative Activity}

The antioxidative activity of magnolol has been confirmed by protection from ischemic injury in neurons in stroke animal models (SAM), as shown by suppressive expression of nitrotyrosine, 4-hydroxy-2-nonenal (4-HNE), iNOS, and p-p38 MAPK signaling and downregulation of inflammatory cytokines, including IL-1 $\beta, \mathrm{TNF} \alpha$, and IL-6 [6] (Figure 2). In the assays of the inhibited autoxidation of cumene and styrene, magnolol has been shown to trap 4 peroxyl radicals with a $K_{\text {inh }}$ value of $6.1 \times 10^{4} / \mathrm{M} / \mathrm{s}$ in chlorobenzene and of $6.0 \times 10^{3} / \mathrm{M} / \mathrm{s}$ in acetonitrile. Comparatively, more than 2 peroxyl radicals are trapped by honokiol. This difference is due to a combination of intramolecular hydrogen bonding in magnolol [47]. The review of magnolol and honokiol on their multifunctional antioxidative activity for dermatologic disorders has been made by Shen (2010) [48].

Increased oxidative stress contributes to the development of obesity-related metabolic disorders. Magnolol has been demonstrated to decrease ROS production, upregulate the expression of UCP1, Cd137, Prdm16, Cidea, Tbx1, PGC$1 \alpha$, CPT1, ACSL1, SIRT1, and PLIN, and downregulate the expression of FAS and SREBP1, resulting in browning 
of 3T3-L1 adipocytes, enhancing lipolysis and thermogenesis, and repressing oxidative stress through activation of AMP-activated protein kinase (AMPK), PPAR $\gamma$, and protein kinase A (PKA) signaling pathways [7] (Table 1). Acrolein, a neurotoxin, can induce neurodegenerative disorders through inducing oxidative stress and activating MEK/ERK signaling and mitochondrial caspases, leading to apoptosis in neuroblastoma SH-5Y5Y cells. Magnolol pretreatment effectively attenuates acrolein-mediated oxidative stress through decreasing the production of ROS and inhibiting JNK/mitochondrial caspases, PI3K/MEK/ERK, and PI3K/Akt/FOXO1 signaling pathways [49] (Figure 2). The mechanism of bleomycin-induced pulmonary fibrosis is currently believed to be related to oxidative and inflammatory stresses. Due to antioxidative and anti-inflammatory activity, magnolol has been shown to partly reverse the effects of bleomycin on fibrotic process, as evidenced by downregulation of hydroxyproline content, myeloperoxidase (MPO) activity, and TNF $\alpha$ and transforming growth factor $\beta$ (TGF $\beta$ ) expression and upregulation of SOD expression [65].

On the other hand, aristolochic acids (AA) are nephrotoxic agents, due to their induction of oxidative stress and DNA adducts formation. Magnolol has been found to ameliorate the AA-induced oxidative stress and cell apoptosis in HK-2 cells. However, magnolol worsens overall cell viability in AA-pretreated cells through induction of necrosis, but not autophagy, paraptosis, or accelerated senescence, by causing cell cycle arrest at G1 phase [66]. There is some uncertainty in the interaction between magnolol and drugs, which influences cell viability.

\section{Anticancer Activity}

The anticancer activity of magnolol has been intensively studied in colon and liver cancer cells [67], lung squamous carcinoma CH27 cells [68], L5178Y-ML25 lymphoma [69], and B16-BL6 melanoma [69]. Pretreatment of combination of magnolol with honokiol significantly decreases cell viability and proliferation and increases cell apoptosis in human epidermoid carcinoma A431 cells [10]. In U87MG and LN229 human glioma cells, magnolol, coadministrated with honokiol, has been demonstrated to synergistically inhibit the expression of cyclin A, cyclin D1, and cyclindependent kinase (CDK) 2, CDK4, and CDK6, resulting in cell cycle arrest. These might be associated with decreased expression of p-PI3K, p-Akt, p-p38, p-JNK, and Ki67 and increased expression of $\mathrm{p}$-ERK. In addition, combination of magnolol with honokiol can significantly induce autophagy and apoptosis [11]. In androgen insensitive human prostate cancer DU145 and PC3 cell lines, magnolol significantly inhibits the expression of cyclin A, cyclin B1, cyclin D1, cyclin E, CDK2, CDK4, and pRBp107 and enhances the expression of pRBp130, leading to cell cycle alternations. However, the proteins expression of p16INK4a, p21, and p27 are not changed apparently by magnolol after 24 hours administration [12].

Magnolol at lower doses can cause cell cycle arrest at $\mathrm{G}_{0} / \mathrm{G}_{1}$ phase, decrease the expression of cyclin D1, cyclin A, and CDK2, and increase the expression of p21/Cip1 in human glioblastoma cancer (U373) cells [50] (Table 1). At higher dose $(100 \mu \mathrm{M})$, magnolol increases the expression of $\mathrm{p} 27 / \mathrm{Kip} 1$ and induces cell apoptosis in U373 cells, accompanied by increased phosphorylation of cSrc, ERK, p38, and Akt, but not JNK [51]. In human gallbladder carcinoma (GBC) cells, magnolol arrests cell cycle at $G_{0} / G_{1}$ phase and triggers mitochondria-dependent apoptosis through upregulation of p21 and p53 expression and downregulation of cyclin D1, CDC25A, and CDK2 expression [70]. In cholangiocarcinoma (CCA) cells, magnolol significantly inhibits cell growth, migration, and invasion, accompanied by decreased expression of Ki67, proliferating cell nuclear antigen (PCNA), matrix metalloproteinases 2 (MMP-2), MMP-7, and MMP9. In addition, magnolol causes cell cycle arrest at G1 phase and downregulates the expression of Cyclin $\mathrm{D} 1, \mathrm{p}-\mathrm{I} \kappa \mathrm{B} \alpha$, and p-p65 [52] (Table 1).

In nonsmall cell lung cancer A549, H441, and H520 cell lines (NSCLC), magnolol selectively induces DNA fragmentation, decreases mitochondrial membrane potential $(\Delta \psi \mathrm{m})$, and inhibits cell proliferation. The underlying mechanism might be linked to the release of Bax, Bid, and cytochrome $c$ from mitochondria, but inactivation of caspase-3, -8, and -9. However, there is no obvious cytotoxicity of magnolol to normal human bronchial epithelial cells. These indicate an apoptotic pathway induced by magnolol in not caspasedependent but endonuclease G and cleaved poly(ADPribose) polymerase-dependent manner. In addition, magnolol activates the expression of p38 and JNK and attenuates the activity of PI3K/Akt and ERK1/2 in A549 cells [71]. Magnolol has been shown to inhibit the proliferation of NSCLC cell lines, PGCL3, SK-MES-1, NCI-H460, A549, NCI-H1299. Magnolol causes cell cycles arrest at G2/M phase through inhibition of microtubule polymerization and induces cell apoptosis in a p53-independent manner and cell autophagy in an Akt/mTOR-dependent manner [72].

Invasion and metastasis are the two main factors of cancer cells in response to management failure. Magnolol significantly suppresses the invasive activity through downregulation of NF- $\kappa \mathrm{B} / \mathrm{MMP}-9$ signaling pathway in human breast cancer cell lines, including MDA-MB-231 cells [73]. Cancer cachexia is a complex metabolic syndrome that is featured by body weight loss, skeletal muscle atrophy, anorexia, and inflammation. Combination of magnolol with chemotherapeutic drugs has been developed to improve skeletal muscle atrophy and inhibit body weight loss in bladder cancer in mice. These might be associated with inhibiting the formation of myostatin and activin A, increasing the activity of p-Akt and p-FOXO3, enhancing the expression of IGF-1, p-mTOR, p-p70S6K, and p-4EBP-1, and decreasing the activity of the proinflammatory cytokines [53] (Table 1).

Angiogenesis is closely related to cancer cells invasion and metastasis and promotes cancer development. Vascular endothelial growth factor (VEGF), a critical mediator of angiogenesis, promotes cells proliferation, migration, and survival through interacting with its receptors, such as VEGFR-1 and VEGFR2. Magnolol can significantly inhibit angiogenesis through decreasing tube formation of HUVECs induced by hypoxia and VEGF in chicken chorioallantoic membrane and matrigel plug. In human bladder cancer 
cells (T24), magnolol decreases the production of $\mathrm{H}_{2} \mathrm{O}_{2}$ and the expression of HIF- $1 \alpha$ and increases the degradation of HIF-1 $\alpha$. In addition, magnolol acts as an antagonist to directly bind to VEGFR2, leading to attenuation of Akt/mTOR/p70S6K/4E-BP-1 kinase signaling pathways in hypoxic T24 cells and tumors [74]. In HUVECs, magnolol inhibits VEGF-stimulated proliferation, chemotactic motility, tube formation, and vessel sprouting through blocking the activity of MEK/ERK and PI3K/Akt signaling pathways, but not Src and focal adhesion kinase (FAK) signaling pathways, in a Ras-dependent manner [54].

Retinal neovascularization (RNV) may be the neopathy of vascular occlusions, diabetes, vessel regression, and agerelated macular degeneration. VEGF undoubtedly promotes the development of and becomes the therapeutic target for RNV [8]. Due to hypoxia, activated microglia stimulates the expression of inflammatory cytokines, which significantly contribute to RNV development. Magnolol has been shownto preserve the astrocyte morphology, inactivate microglia, decrease the expression of inflammatory cytokines, and attenuate HIF-1 $\alpha /$ VEGF signaling, leading to reduction of RNV [9]. Consistently, magnolol exhibits antiangiogenic activity through induction of ROS and suppressive expression of platelet endothelial cell adhesion molecule (PECAM), which is an endothelial biomarker in mouse embryonic stem (mES)/embryoid body (EB)-derived endothelial-like cells. This might be associated with inactivation of MAPK (p38, JNK, and ERK) and PI3K/Akt/mTOR signaling pathways by magnolol [75].

\section{Neuroprotective Activity}

Dopaminergic neurons degeneration is one of the main pathological characteristics of Parkinson's disease (PD). Magnolol has been shown the neuroprotective activity to reverse the damage induced by 1-methyl-4-phenyl-1,2,3,6tetrahydropyridine (MPTP) using ${ }^{18} \mathrm{~F}-\mathrm{FP}-(+)$-DTBZ animal positron emission tomography (PET) [13]. Cholinergic deficits and neuronal dysfunction contribute to Alzheimer's disease (AD). Magnolol has been demonstrated to improve the learning and memory impairment induced by scopolamine (Scop) in mice, as evidenced by restoring the activity of acetyl cholinesterase (AChE), the total contents of SOD and NOS, and the concentration of MDA. These might be associated with the antioxidative activity of magnolol [55] (Table 1). Amyloidogenic protein is also an important causative factor for development of AD, Parkinson's diseases (PD), and type II diabetes. Human calcitonin (hCT), a typical amyloidogenic peptide, aggregates into oligomeric intermediates, which are the most toxic factors during amyloid aggregation and induce cell apoptosis. Magnolol has been shown to not only inhibit the aggregation and amyloid formation of hCT, but also disassemble the preformed aggregation of hCT, through interacting with hCT directly. In addition, magnolol can significantly ameliorate the cytotoxicity caused by hCT aggregates [14].

Recently, a number of research studies report that magnolol exhibits antidepressant activity in rodent models [7678]. Magnolia officinalis and its major component magnolol have been demonstrated to shorten the immobility time in the forced swim test (FST) in mice, indicating their antidepressant activity [76]. In the unpredictable chronic mild stress (UCMS) rats model, the expressions of brain-derived neurotrophic factor (BDNF) and glial fibrillary acidic protein (GFAP) are downregulated, and the sucrose consumption and the locomotor activity are significantly attenuated. Magnolol at the doses of 20 and $40 \mathrm{mg} / \mathrm{kg}$ shows antidepressant activity and effectively reverses the effects of UCMS $[77,78]$. Consistently, magnolol also shows antidepressant activity in an olfactory bulbectomy (OBX) mice model by improvement of impaired hippocampal neurogenesis and increased phosphorylation of extracellular signaling, Akt, ERK, and CREB [79]. In chronic hormone corticosterone (CORT)-induced depressive rats model, the immobility time of FST and tail suspension test (TST) are decreased, along with decreased expression of BDNF, 5-hydroxytryptamine (5-HT), and norepinephrine (NE). Magnolol significantly ameliorates the depressive-like behaviors, decreases CORT levels, and increases the expression of BDNF, 5-HT, and NE in CORT-induced mice [56].

Increasing evidence reports that neuroinflammation, neuroendocrine, and oxidative stress contribute to the development of depression. In chronic mild stress (CMS) mice models, magnolol can significantly downregulate the expression of IL- $1 \beta$, TNF- $\alpha$, IL- 6 , and MDA, upregulate the levels of SOD and glutathione peroxidase (GSH-Px), and attenuate the activity of hypothalamic-pituitary-adrenal (HPA) signaling pathway [80]. Trimethyltin (TMT) is a useful agent for creating a neurodegenerative model. It has been demonstrated that TMT can induce oxidative stress and trigger cell necrosis/apoptosis. Magnolol pretreatment can significantly reverse the damage induced by TMT, as indicated by decreased production of ROS, inactivation of $\mathrm{NF}-\kappa \mathrm{B}$, JNK, and p38 MAPK signaling, and attenuation of microglial activation in vitro and in vivo [81].

The effects of magnolol on neural injury and bloodbrain barrier (BBB) induced by ischemia-reperfusion (I/R) have been investigated. Magnolol, at the doses of 1.4, 7.0, and $35 \mu \mathrm{g} / \mathrm{kg}$, can significantly decrease cerebral infarct volume, brain water content, and the exudation of Evans blue in mice with I/R. In the primary microglial cells, magnolol has been shown to inhibit the release of $\mathrm{NO}$ and the expression of TNF $\alpha$ and p 65 translocation induced by LPS. In oxygen and glucose deprivation-reperfusion models of the media of brain microvascular endothelial cells (BMECs) and $\mathrm{BBB}$, magnolol significantly ameliorates the expression of TNF $\alpha$, IL-1 $\beta$, and EphA2 phosphorylation and elevates the production of zonula occludens-1 (ZO-1) and occludin [57] (Table 1). In ischemic stroke rat models, magnolol has been shown to ameliorate brain edema, reduce infarct volume, and increase neurological score. This might be associated with the anti-inflammatory activity of magnolol, as indicated by downregulation of IL- $1 \beta, \mathrm{TNF} \alpha, \mathrm{Bax}$, and Ac-FOXO1 expression and upregulation of Bcl-2 and SIRT1 expression [82]. In traumatic brain injury, magnolol can significantly decrease the levels of glycerol and hydroxyl radical and increase the expression of TGF- $\beta 1$ in hippocampus, leading to reduction of infarct volume and neuronal apoptosis [83]. 


\section{Cardiovascular Protection Activity}

Recently, clinical evidence shows that patients with prehypertension (high-normal blood pressure) are more likely to progress to hypertension than those who are with normal or optimal blood pressure [84]. Magnolol has been demonstrated to restore insulin-mediated activity of Akt and eNOS and of vasolidation of aorta, upregulate the expression of PPAR $\gamma$, and downregulate the expression of TRB3 in spontaneous hypertensive rats (SHR) and cultured human umbilical vein endothelial cells (HUVECs) [15] (Table 1). The activity of cell adhesion molecules (CAMs) and the attachment of leukocytes to the endothelium are important for cardiovascular disorders. Magnolol has been shown to inhibit the phosphorylation of $\mathrm{JNK} / \mathrm{p} 38$, the translocation of $\mathrm{HuR}$, the activation of NF- $\kappa \mathrm{B}$, and the expression of vascular CAM-1 (VCAM-1), leading to reduction of leukocyte adhesion in $\mathrm{TNF} \alpha$-treated human aortic endothelial cells (HAECs) [58].

Vascular smooth muscle cells (VSMCs) basically reside in quiescent form, and their enhanced proliferation and migration induced by TNF $\alpha$ contribute to atherosclerotic and restenotic lesions formation. Magnolol has been demonstrated to cause cell cycle arrest at $G_{0} / G_{1}$, downregulate the expression of cyclin D1, cyclin E, CDK2, and CDK4, and attenuate the activity of p-ERK1/2 and NF- $\kappa \mathrm{B}$ signaling pathways [16] (Table 1). Similarly, magnolol inhibits the proliferation of VSMCs induced by platelet-derived growth factor (PDGF)-BB through reduction of intracellular ROS and decreased expression of Ras, MEK, and ERK1/2 [85]. In addition, the migration of VSMCs can be strongly inhibited by magnolol through attenuation of cytoskeletal remodeling signaling pathway without affecting the activity of MMPs, as evidenced by suppressive expression of $\beta 1$-integrin, RhoA, Cdc42, p-FAK, and p-MLC20 in vivo and in vitro, leading to inhibition of neointima formation [86].

\section{Metabolism-Regulating Activity}

Combinational activation of retinoid X receptor $\alpha(\mathrm{RXR} \alpha)$ and PPAR $\gamma$ is believed to increase their effects on glucose and lipid metabolism synergistically. Magnolol acts as a dual agonist for activating both $\operatorname{RXR} \alpha$ and PPAR $\gamma$. However, there is a biased agonism of magnolol to promote the transcriptional activity of PPAR-response element (PPRE), which is regulated by the heterodimer of RXR $\alpha: \operatorname{PPAR} \gamma$, instead of RXR-response element (RXRE) by $\operatorname{RXR} \alpha: \operatorname{RXR} \alpha$ [87]. To further investigate the modulating activity of magnolol in lipid metabolism in vivo, a transgenic knock-in mice carrying apolipoprotein A5 (APOA5) c.553G $>$ T variant has been established. Magnolol has been found to decrease the levels of the plasma triglyceride in the transgenic mice and increase the expression of lipoprotein lipase (LPL) in 3T3-L1 preadipocytes. These indicate the facilitation of triglyceride metabolism and reduction of hyperlipidemia [18]. Magnolol enhances the differentiation of adipocytes and the uptake of glucose, leading to amelioration of glucose level in 3T3L1 cells [59]. Potent glucosidase inhibitors are able to retard glucose absorption and reduce blood glucose levels. Magnolol shows the inhibitory activity on $\alpha$-glucosidase with $\mathrm{IC}_{50}$ value of $2.0 \mu \mathrm{M}$ [62]. Protein tyrosine phosphatase-1B (PTP1B) is a major nontransmembrane phosphotyrosine phosphatase and acts as a negative regulator of the insulin signaling pathway. It has been demonstrated that magnolol inhibits the activity of PTP1B with $\mathrm{IC}_{50}$ value of $24.6 \mu \mathrm{M}$ [63]. Peroxisome proliferator-activated receptor gamma (PPAR $\gamma)$ agonists are used for the treatment of type 2 diabetes and metabolic syndrome. Being an agonist, magnolol activates $\operatorname{PPAR} \gamma$ with $K i$ value of 2.04 $\mu \mathrm{M}$ [64] (Table 2). Magnolol has been reported to induce lipolysis in lipid-laden RAW 264.7 macrophages through attenuation of adipose differentiation-related protein (ADRP) expression in a cAMP-PKA-independent manner [17] (Table 1).

Liver X receptors (LXR) participate in the regulatory processes of many physiological activities, including metabolism of glucose, cholesterol, and fat. It has been demonstrated that magnolol can combine with LXR $\alpha$ dose-dependently and regulate its downstream genes expression in HepG2 and THP-1 cell lines [88]. High-fat diet (HFD) consumption has been linked to activation of hepatic steatosis and liver dysfunction. LXR $\alpha$ activation leads to increased expression of sterol regulatory element binding protein -1c (SREBP-1c) and lipogenic genes. These can be abrogated by treatment of magnolol and honokiol through upregulation of AMPK, which exhibits inhibitory activity to LXR $\alpha$-SREBP-1c signaling pathway [89].

Consistently, activation of Akt/AMPK/PPAR $\alpha$ signaling and attenuation of MAPK/NF- $\kappa$ B/SREBP- $1 c$ signaling by magnolol have been linked to its effects against steatosis and hyperlipidemia, as indicated by suppression of oleic acid (OA)-induced triglyceride (TG) accumulation, ROS production, and TNF $\alpha$ expression in HepG2 cells [90]. In HFD-fed mice, magnolol can significantly decrease the weight of white adipose tissue (WAT) and the size of adipocyte and reverse insulin resistance. These might be the results of augment of energy expenditure and adipose fatty acid oxidation and attenuation of the activity of fatty acid synthase and the expression of genes relating to adipocyte differentiation, fatty acid synthesis, and desaturation in WAT. In addition, magnolol has been shown to ameliorate the expression of proinflammatory genes and enhance the level of the plasma IL-10 [91].

Methylglyoxal (MG) is a precursor of advanced glycation end-products (AGEs), which contribute to insulin resistance. In RIN-m5F $\beta$-cells, MG causes decreased viability and impaired insulin secretion, which can be reversed by magnolol. In addition, magnolol is involved in promotion of $\beta$-cell survival and functions, as indicated by increased expression of Ins2, PDX1, p-AMPK, SIRT1, and PGC- $1 \alpha$. Furthermore, magnolol enhances the activity of glyoxalase I and attenuates the expression of MG-mediated protein adducts, leading to protection against MG-induced glycation in RIN-m5F $\beta$-cells [92].

\section{Ion-Mediating Activity}

Magnolol has been reported to show different responses to $\mathrm{Ca}^{2+}$ signaling in various cell types. Magnolol can increase 
cytoplasmic free $\mathrm{Ca}^{2+}$ through induction of $\mathrm{Ca}^{2+}$ mobilization in human neuroblastoma SH-SY5Y cells and primary rat cortical neurons [93] and enhance the cytosolic $\mathrm{Ca}^{2+}$ concentration through stimulatory release of $\mathrm{Ca}^{2+}$ from internal stores and external influx across the plasma membrane [94]. Magnolol also induces the rise of cytosolic $\mathrm{Ca}^{2+}$ concentration through stimulation of phospholipase C (PLC)-dependent release of $\mathrm{Ca}^{2+}$ partially from endoplasmic reticulum and induction of $\mathrm{Ca}^{2+}$ entry by PKC-mediated store-managed $\mathrm{Ca}^{2+}$ mobilization, leading to $\mathrm{Ca}^{2+}$ signalingdependent cell death in oral cancer cells [95]. On the other hand, magnolol blocks the influx of $\mathrm{Ca}^{2+}$ through voltage-gate $\mathrm{Ca}^{2+}$ channels (VGCC), leading to relaxation of porcine tracheal smooth muscle [96]. The inhibitory effects of magnolol on uterine contraction might be abolished by abrogation of external $\mathrm{Ca}^{2+}$ influx induced by $\operatorname{PGF}(2 \alpha)$ and high $\mathrm{K}^{+}$[97]. And, L-type $\mathrm{Ca}^{2+}$ channel activity is attenuated by magnolol, which inhibits colonic smooth muscle contraction [98]. This alternation of intracellular $\mathrm{Ca}^{2+}$ mobilization induced by magnolol through VGCC is also confirmed in guinea pig [99].

In enterotoxigenic Escherichia Coli (ETEC)-triggered diarrhea mice, magnolol has been found to increase the levels of $\mathrm{Cl}^{-}$and $\mathrm{K}^{+}$and the mRNA expression of calmodulin $1(\mathrm{CaM})$, potassium large conductance calcium-activated channels (BK) $\alpha$, and BK $\beta 3$ and decrease the mRNA expression of IP3R1, PKC, potassium small conductance calciumactivated channels (SK)1, SK2, SK3, SK4, and BK $\beta 4$. However, magnolol does not influence the mRNA expression of CaMKII $\alpha$, CaMKII $\beta$, IP3R2, IP3R3, BK $\beta 1, \mathrm{BK} \beta 2$, and ryanodine receptor (RYR) 1 [100].

\section{Clinical Prospective}

The emerging multidrug-resistant bacteria cause life-threatening infections. Staphylococcus aureus shows resistance to wide spectrum $\beta$-lactam antibiotics, such as methicillin and oxacillin. Infection caused by methicillin-resistant $S$. aureus (MRSA) poses a serious global issue. Magnolol and honokiol have been reported to show antibacterial activity against MRSA, methicillin-susceptible S. aureus (MSSA), and $S$. aureus dose-dependently. Importantly, magnolol exhibits synergistic activity with oxacillin against 13 clinical isolated MRSA. The underlying mechanism might be associated with downregulation of the resistant genes expression in $S$. aureus, including mecA, mecI, femA, and fem $B$ [101]. In addition, magnolol significantly decreases ROS production and inflammatory cytokines expression in response to $S$. aureus in mouse macrophages. The internalization of $S$. aureus by human alveolar epithelial cells is also attenuated by magnolol [102]. Magnolol does not show any antagonistic effects on the 10 MRSA strains, when it is combined with the antibacterial agents synergistically. $\mathrm{MIC}_{50}$ of magnolol in combination decreases from $16 \mathrm{mg} / \mathrm{L}$ to $1-4 \mathrm{mg} / \mathrm{L}$ and the antibacterial agent decreases from $8-128 \mathrm{mg} / \mathrm{L}$ to $2-64 \mathrm{mg} / \mathrm{L}$. Importantly, magnolol shows reversal effects on MRSA to resensitize to amikacin and gentamicin [103]. These suggest that magnolol demonstrates the potential for managing $\beta$-lactam treatments against the resistant strains of infectious bacteria.

Candida spp. has been considered as a critical pathogen for nosocomial bloodstream infection. Due to prolonged exposure to azoles, Candida spp. with azoles resistance causes therapeutic failure with a high rate of mortality. Magnolol has been shown to prolong the survival of Candida albicans-infected nematodes through inhibiting Rasl-cAMPEfgl signaling-mediated adhesion, transition from yeast to hypha, and biofilm formation of C. albicans [104]. The minimum inhibitory concentration (MIC) of magnolol against C. albicans and nonalbicans Candida is $10-40 \mu \mathrm{g} / \mathrm{mL}$. The $\mathrm{BMIC}_{90}$ (minimum inhibitory concentration that inhibits $90 \%$ biofilm formation) value of magnolol is $20-160 \mu \mathrm{g} / \mathrm{mL}$ [105]. Magnolol has been found to exhibit synergistic effects with fluconazole to inhibit the activity of Candida albicans through induction of higher concentration of intracellular antifungals. The molecular mechanism might be associated with competition of magnolol with $\mathrm{ABC}$ transporter Cdrlp substrates and enhancement of the ergosterol biosynthesis pathway [106]. Magnolol can effectively inhibit growth and biofilm formation in oral Candida isolates with MIC value of $16-64 \mathrm{~g} / \mathrm{mL}$. The possible mechanism might involve the disruption of cell membrane by magnolol by using confocal scanning laser microscopy and transmission electron microscopy. In addition, molecular docking reveals that magnolol might interact with ergosterol directly in the fungal cell membrane [107]. In a six-month clinical study, unsupervised brushing with a dentifrice containing $0.3 \%$ Magnolia extract significantly reduces dental plaque and gingivitis, as indicated by reduction of gingival index (GI) and Quigley and Hein index (QHI) compared to placebo [108]. Consistently, Magnolia chewing gum can also reduce plaque acidogenicity, salivary mutans streptococci concentration, and gingival bleeding after 30 days of treatment [109], indicating beneficial effects of magnolol on oral health.

Ligature-induced periodontitis leads to the alveolar bone loss posing a serious oral-health issue in clinical practice. Magnolol can significantly protect against alveolar bone resorption, osteoclast growth on bony surface, and the protein expression of receptor activator of nuclear factor$\kappa \mathrm{B}$ ligand (RANKL). In addition, magnolol also reduces the expression of iNOS, COX-2, MMP-1, MMP-13, ROS, and NF$\kappa \mathrm{B}$ activation in gingival tissues. In vitro, magnolol inhibits the growth of Porphyromonas gingivalis and Aggregatibacter actinomycetemcomitans with both $\mathrm{IC}_{50}$ values of about $100 \mu \mathrm{M}$, the differentiation of osteoclast from RAW264.7 macrophages induced by RANKL, and the activity of tartrateresistant acid phosphatase (TRAP) in differentiated osteoclast [61]. The underlying mechanism of magnolol in mediating RNAKL-triggered osteoclast differentiation and bone resorption is related to suppression of NFATcl nuclear translocation, as evidenced by inhibition of ROS generation, $\mathrm{MAKP} / \mathrm{c}-$ fos/AP-1 signaling, and NF- $\kappa \mathrm{B}$ signaling and increased expression of HO-1 [110].

Magnolol lacks direct antibacterial activity, but it inhibits the enzyme activity of New Delhi metallo- $\beta$-lactamase-1 (NDM-1) by directly interacting with the catalytic pocket with an $\mathrm{IC}_{50}$ value of $7.47 \mu \mathrm{g} / \mathrm{mL}$ and restores the activity of 


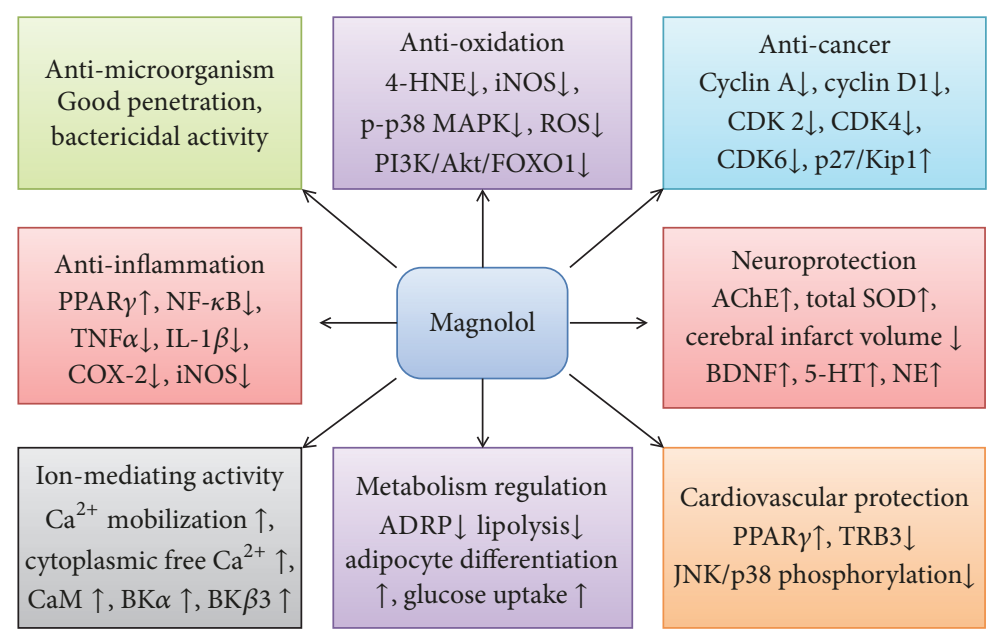

Figure 3: The multifunctional activities of magnolol. Magnolol has been shown to result in anti-inflammation, antimicroorganism, antioxidation, anticancer, neuroprotection, cardiovascular protection, metabolism regulation, and ion-mediating activity.

meropenem against Escherichia Coli ZC-YN3 with decreased MICs by 4 -fold [60]. Magnolol has been reported to inhibit endothelial cell activity during pressure-regulated venous remodeling processes, which play a crucial role in varicose and spider veins development. The possible underlying mechanism might be associated with the antiproliferative and antioxidative activity of magnolol through enhancement of HO-1 signaling and downregulation of cell proliferation, ERK1/2 activity, gelatinase activity, and ROS baseline production. However, the formation of endothelial capillary sprout is not influenced by magnolol [111]. In concanavalin A (ConA)-stimulated transformation from CD4+ T cells to CD4+T helper (Th17) cells in liver, magnolol significantly inhibits this cellular polarization, Th17 cell differentiation, and IL-17A production. In addition, magnolol suppresses the activation of hepatic stellate cells in fibrotic liver, as shown by decreased expression of $\alpha$-smooth muscle actin ( $\alpha$-SMA), desmin, TGF $\beta 1$, and activin A. These might be related to partial blockade of Smad3 signaling pathway by magnolol in LX2 cells [112].

Heat stress (HS) adversely affects livestock in summer. It has been reported that HS causes intestinal epithelial cell line (IEC-6) injury and cell cycle arrest at G1 phase, as indicated by increased expression of p21 and p27 and decreased expression of E2F1, pRb, cyclin D1, and CDK4. Magnolol pretreatment protects against HS-triggered injury in IEC-6 cells effectively [113]. Magnolol has been demonstrated to show antiphotoaging activity in UV-irradiated hairless mice, as evidenced by reduction of the average length and depth of wrinkles, downregulation of MMP1, MMP-9, and MMP-13 expression, and attenuation of MAPKs phosphorylation, including $\mathrm{p} 38, \mathrm{ERK} 1 / 2$, and JNK [114]. In China, the effects of Magnolia officinalis on gastrointestinal motility disorder have been intensively investigated [115]. Magnolia officinalis improves gastrointestinal motility disorder in rats by increasing the concentration of L-glutamate, L-tryptophan, and serotonin and protecting gastrointestinal barrier. Similarly, magnolol mainly affects 10 major metabolic pathways, of which tryptophan metabolism is the most important pathway associated with gastrointestinal tract. The underlying mechanism might be related to reduction of $\mathrm{NO}$ production, attenuation of $\mathrm{NO}$ functions in relaxing the gastrointestinal smooth muscle, and promotion of gastrointestinal peristalsis and motility, secretion, absorption of nutrients by increasing serotonin content [116]. Consistently, magnolol enhances the antiinflammatory capacities in intestine, elongates the villus height and crypt depth, and reduces goblet cell numbers, leading to protection of intestinal mucosal integrity and amelioration of gastrointestinal dysfunction [117].

Magnolol, a natural compound with versatile biological functions, has been demonstrated to be safe with absence of any mutagenic and genotoxic potentials $[19,118]$. In addition, magnolol exhibits antimutagenic activity effectively [119]. Magnolia bark extract (MBE), consisting of $94 \%$ magnolol, has the oral LD50 value with more than $50 \mathrm{~g} / \mathrm{kg}$ body weight [118]. No obvious sign of toxicity has been obtained for MBE (60-480 mg/kg b.w./d for 21 days and $60-240 \mathrm{mg} / \mathrm{kg}$ b.w./d for 90 days) [120]. However, magnolol (no less than $0.5 \mathrm{mg} / \mathrm{kg}$ b.w.) has been reported to prolong the mice tail bleeding time at low dose of $10 \mathrm{mg} / \mathrm{kg}$ b.w., indicating the potential for developing an antihemostatic agent. Additionally, magnolol has showed spasmolytic effects on uterine muscle contraction. This makes it possible for magnolol to be used for treatment of gynecological disturbances and dysfunctions associated with an increase in uterine muscular activity. However, the effects of magnolol in pregnancy are still not justified. On perception of safety for natural product, magnolol could be used as a sedative, due to its GABAergic and cannabimimetic activity [121]. Management of abuse/misuse of magnolol should be deeply discussed.

\section{Concluding Marks}

In this review, we mainly discuss the biological activities of magnolol (Figure 3 ) in the last 10 years. Mechanistically, 
magnolol shows inhibitory activity on NF- $\kappa$ B and MAPK signaling pathways and their target genes expression, leading amelioration of inflammation and oxidation. These are available for the strategies in protecting neural and cardiovascular diseases. In addition, magnolol mediates the expression of proliferation-related proteins, which might be the potential targets for managing cancers. Metabolism regulation and ion mediation are the two critical cellular physiological processes, during which imbalanced homeostasis may result in severe pathology and be restored by magnolol. These findings have greatly increased the interest in bridging magnolol to the clinic as a promising therapeutic agent.

However, information in this review on structural modifications of magnolol has been neglected. Unfortunately, the low water solubility, the low bioavailability, and the rapid metabolism of magnolol dramatically limit its clinic application, although many useful approaches have been under investigation. Most studies on the biological activities of magnolol in vitro are focusing on the parent form. However, the increasing evidence shows that the parent form of magnolol is not present in the systemic circulation. Therefore, whether the knowledge of magnolol-benefit obtained in the in vitro studies can predict the actual effects of magnolol in vivo is still unclear. And not even one clinical data has been obtained to show the efficacy of magnolol. To fully rationalize the potential of magnolol, more efforts and clinical trials are needed. In addition, the metabolites of magnolol also exhibit great biological potentials. Investigation on the functions of the metabolites of and the derivatives of magnolol in vivo and in vitro may lead to exploration of new drugs.

\section{Conflicts of Interest}

The authors declare no conflicts of interest.

\section{Authors' Contributions}

Longhuo $\mathrm{Wu}$ and Hao Huang provided the idea of this paper. Jianhong Zhang, Zhixi Chen, and Xianhua Huang contributed equally to this study. All authors approved the final paper.

\section{Acknowledgments}

This study was financially supported by the National Natural Science Foundation of China (81660371 and 81860388), the National Science Foundation of Jiangxi Province (20161BAB215219, 20171BAB215058, and 20171BAB205107), Scientific Research Fund of Jiangxi Provincial Education Department (GJJ160972, GJJ160990, GJJ170886, and GJJ180820), The Youth Jinggang Scholar Program in Jiangxi Province, and Innovative Teamwork Project of Gannan Medical University (TD201707).

\section{References}

[1] L. Zhu, G. Ge, H. Zhang et al., "Characterization of hepatic and intestinal glucuronidation of magnolol: Application of the relative activity factor approach to decipher the contributions of multiple UDP-glucuronosyltransferase isoforms," Drug Metabolism and Disposition, vol. 40, no. 3, pp. 529-538, 2012.

[2] R. C. Reddy, V. G. Keshamouni, S. H. Jaigirdar et al., "Deactivation of murine alveolar macrophages by peroxisome proliferator-activated receptor- $\gamma$ ligands," American Journal of Phys-iology-Lung Cellular and Molecular Physiology, vol. 286, no. 3, pp. L613-L619, 2004.

[3] P. Shen, Z. Zhang, Y. He et al., "Magnolol treatment attenuates dextran sulphate sodium-induced murine experimental colitis by regulating inflammation and mucosal damage," Life Sciences, vol. 196, pp. 69-76, 2018.

[4] S.-H. Lu, W.-L. Hsu, T.-H. Chen, and T.-C. Chou, "Activation of Nrf2/HO-1signaling pathway involves the anti-inflammatory activity of magnolol in Porphyromonas gingivalis lipopolysaccharide-stimulated mouse RAW 264.7 macrophages," International Immunopharmacology, vol. 29, no. 2, pp. 770-778, 2015.

[5] J. Park, J. Lee, E. Jung et al., "In vitro antibacterial and antiinflammatory effects of honokiol and magnolol against Propionibacterium sp," European Journal of Pharmacology, vol. 496, no. 1, pp. 189-195, 2004.

[6] J. H. Chen, H. C. Kuo, K. F. Lee, and T. H. Tsai, "Magnolol protects neurons against ischemia injury via the downregulation of p38/MAPK, CHOP and nitrotyrosine," Toxicology and Applied Pharmacology, vol. 279, no. 3, pp. 294-302, 2014.

[7] H. A. Parray, J. Lone, J. P. Park, J. W. Choi, and J. W. Yun, "Magnolol promotes thermogenesis and attenuates oxidative stress in 3T3-L1 adipocytes," Nutrition Journal , vol. 50, pp. 8290, 2018.

[8] J. W. Miller, J. Le Couter, E. C. Strauss, and N. Ferrara, "Vascular endothelial growth factor a in intraocular vascular disease," Ophthalmology, vol. 120, no. 1, pp. 106-114, 2013.

[9] B. Yang, Y. Xu, S. Yu, Y. Huang, L. Lu, and X. Liang, "Antiangiogenic and anti-inflammatory effect of Magnolol in the oxygen-induced retinopathy model," Inflammation Research, vol. 65, no. 1, pp. 81-93, 2016.

[10] C. Chilampalli, X. Zhang, R. S. Kaushik et al., "Chemopreventive effects of combination of honokiol and magnolol with $\alpha$-santalol on skin cancer developments," Drug Discoveries \& Therapeutics, vol. 7, no. 3, pp. 109-115, 2013.

[11] Y.-C. Cheng, D.-Y. Hueng, H.-Y. Huang, J.-Y. Chen, and Y. Chen, "Magnolol and honokiol exert a synergistic anti-tumor effect through autophagy and apoptosis in human glioblastomas," Oncotarget, vol. 7, no. 20, pp. 29116-29130, 2016.

[12] B. T. McKeown, L. McDougall, A. Catalli, and R. A. R. Hurta, "Magnolol causes alterations in the cell cycle in androgen insensitive human prostate cancer cells in vitro by affecting expression of key cell cycle regulatory proteins," Nutrition and Cancer, vol. 66, no. 7, pp. 1154-1164, 2014.

[13] C. C. Weng, Z. A. Chen, K. T. Chao et al., "Quantitative analysis of the therapeutic effect of magnolol on MPTP-induced mouse model of Parkinson's disease using in vivo 18F-9-fluoropropyl(+)-dihydrotetrabenazine PET imaging," PLoS One, vol. 12, no. 3, Article ID e0173503, 2017.

[14] C. Guo, L. Ma, Y. Zhao et al., "Inhibitory effects of magnolol and honokiol on human calcitonin aggregation," Scientific Reports, vol. 5, no. 1, Article ID 13556, 2015.

[15] X. Liang, W. Xing, J. He et al., "Magnolol administration in normotensive young spontaneously hypertensive rats postpones the development of hypertension: Role of increased PPAR 
gamma, reduced TRB3 and resultant alleviative vascular insulin resistance," PLoS ONE, vol. 10, no. 3, Article ID e0120366, 2015.

[16] R. Karki, O.-M. Ho, and D.-W. Kim, "Magnolol attenuates neointima formation by inducing cell cycle arrest via inhibition of ERK1/2 and NF-kappaB activation in vascular smooth muscle cells," Biochimica et Biophysica Acta (BBA) - General Subjects, vol. 1830, no. 3, pp. 2619-2628, 2013.

[17] J.-S. Chen, Y.-L. Chen, A. S. Greenberg, Y.-J. Chen, and S.-M. Wang, "Magnolol stimulates lipolysis in lipid-laden RAW 264.7 macrophages," Journal of Cellular Biochemistry, vol. 94, no. 5, pp. 1028-1037, 2005.

[18] C. Chang, X. Lin, Y. Lin et al., "Magnolol-mediated regulation of plasma triglyceride through affecting lipoprotein lipase activity in apolipoprotein A5 knock-in mice," PLoS ONE, vol. 13, no. 2, p. e0192740, 2018.

[19] A. Sarrica, N. Kirika, M. Romeo, M. Salmona, and L. Diomede, "Safety and toxicology of magnolol and honokiol," Planta Medica, vol. 84, no. 16, pp. 1151-1164, 2018.

[20] S.-B. Kim, H. E. Kang, H.-J. Cho et al., "Metabolic interactions of magnolol with cytochrome P450 enzymes: Uncompetitive inhibition of CYP1A and competitive inhibition of CYP2C," Drug Development and Industrial Pharmacy, vol. 42, no. 2, pp. 263-269, 2016.

[21] Y. Huang, C. Liu, S. Liu, Z. Liu, S. Li, and Y. Wang, "In vitro metabolism of magnolol and honokiol in rat liver microsomes and their interactions with seven cytochrome P substrates ", Rapid Communications in Mass Spectrometry, vol. 33, no. 2, pp. 229-238, 2019.

[22] S.-B. Kim, K.-S. Kim, H.-M. Ryu et al., "Modulation of rat hepatic CYP1A and 2C activity by honokiol and magnolol: Differential effects on phenacetin and diclofenac pharmacokinetics in vivo," Molecules, vol. 23, no. 6, 2018.

[23] Y.-L. Sheng, J.-H. Xu, C.-H. Shi et al., "UPLC-MS/MS-ESI assay for simultaneous determination of magnolol and honokiol in rat plasma: Application to pharmacokinetic study after administration emulsion of the isomer," Journal of Ethnopharmacology, vol. 155, no. 3, pp. 1568-1574, 2014.

[24] S.-P. Lin, S.-Y. Tsai, P.-D. Lee Chao, Y.-C. Chen, and Y.-C. Hou, "Pharmacokinetics, bioavailability, and tissue distribution of magnolol following single and repeated dosing of magnolol to rats," Planta Medica, vol. 77, no. 16, pp. 1800-1805, 2011.

[25] V. Rempel, A. Fuchs, S. Hinz et al., "Magnolia extract, magnolol, and metabolites: Activation of cannabinoid CB2 receptors and blockade of the related GPR55," ACS Medicinal Chemistry Letters, vol. 4, no. 1, pp. 41-45, 2013.

[26] M. Hattori, Y. Endo, T. Namba, S. Takebe, K. Kobashi, and N. Fukasaku, "Metabolism of magnolol from Magnoliae cortex. II. Absorption, metabolism and excretion of [ring-14C] magnolol in rats," Chemical \& Pharmaceutical Bulletin, vol. 34, no. 1, pp. 158-167, 1986.

[27] M. Homma, K. Oka, H. Kobayashi et al., "Liquid chromatographic determination of magnolol in urine collected from volunteers after a single dose of Saiboku-To, an oriental herbal medicine for bronchial asthma," Journal of Pharmacy and Pharmacology, vol. 45, no. 9, pp. 839-841, 1993.

[28] H. Sun, X. Zhou, and B. Wu, "Accurate identification of UDP-glucuronosyltransferase 1A1 (UGT1A1) inhibitors using UGT1A1-overexpressing HeLa cells," Xenobiotica, vol. 45, no. 11, pp. 945-953, 2015.

[29] L. Zhu, G. Ge, Y. Liu et al., "Potent and selective inhibition of magnolol on catalytic activities of UGT1A7 and 1A9," Xenobiotica, vol. 42, no. 10, pp. 1001-1008, 2012.
[30] L. Yang, L. Zhu, G. Ge et al., "Species-associated differences in the inhibition of propofol glucuronidation by magnolol," Journal of the American Association for Laboratory Animal Science, vol. 53, no. 4, pp. 408-411, 2014.

[31] H. Shen, S. Liu, P. Ding, L. Wang, J. Ju, and G. Liang, "Enhancement of oral bioavailability of magnolol by encapsulation in mixed micelles containing pluronic F127 and L61," Journal of Pharmacy and Pharmacology, vol. 70, no. 4, pp. 498-506, 2018.

[32] S.-P. Lin, Y.-C. Hou, T.-Y. Liao, and S.-Y. Tsai, "Enhancing the bioavailability of magnolol in rabbits using melting solid dispersion with polyvinylpyrrolidone," Drug Development and Industrial Pharmacy, vol. 40, no. 3, pp. 330-337, 2014.

[33] T. Tsai, C.-Y. Kao, C.-L. Chou, L.-C. Liu, and T.-C. Chou, "Protective effect of magnolol-loaded polyketal microparticles on lipopolysaccharide-induced acute lung injury in rats," Journal of Microencapsulation, vol. 33, no. 5, pp. 401-411, 2016.

[34] M. H. Lin, M. Chen, T. Chen, H. Chang, and T. Chou, "Magnolol ameliorates lipopolysaccharide-induced acute lung injury in rats through PPAR- $\gamma$-dependent inhibition of NF- $\kappa \mathrm{B}$ activation," International Immunopharmacology, vol. 28, no. 1 , pp. 270-278, 2015.

[35] W. Chunlian, W. Heyong, X. Jia, H. Jie, C. Xi, and L. Gentao, "Magnolol inhibits tumor necrosis factor- $\alpha$-induced ICAM1 expression via suppressing NF- $\kappa \mathrm{B}$ and MAPK signaling pathways in human lung epithelial cells," Inflammation, vol. 37, no. 6, pp. 1957-1967, 2014.

[36] L. Zhao, H. Xiao, H. Mu et al., "Magnolol, a natural polyphenol, attenuates dextran sulfate sodium-induced colitis in mice," Molecules, vol. 22, no. 7, p. 1218, 2017.

[37] Y. Zhang, L.-T. Fu, and F. Tang, "The protective effects of magnolol on acute trinitrobenzene sulfonic acid-induced colitis in rats," Molecular Medicine Reports, vol. 17, no. 3, pp. 34553464, 2018.

[38] J. Luo, Y. Xu, M. Zhang, L. Gao, C. Fang, and C. Zhou, "Magnolol inhibits LPS-induced inflammatory response in uterine epithelial cells: Magnolol inhibits LPS-induced inflammatory response," Inflammation, vol. 36, no. 5, pp. 997-1003, 2013.

[39] W. Wei, L. Dejie, S. Xiaojing et al., "Magnolol inhibits the inflammatory response in mouse mammary epithelial cells and a mouse mastitis model," Inflammation, vol. 38, no. 1, pp. 16-26, 2015.

[40] B. Miao, S. Zhang, H. Wang, T. Yang, D. Zhou, and B.-E. Wang, "Magnolol pretreatment prevents sepsis-induced intestinal dysmotility by maintaining functional interstitial cells of Cajal," Inflammation, vol. 36, no. 4, pp. 897-906, 2013.

[41] C. Tang, C. Lai, P. Huang et al., "Magnolol reduces renal ischemia and reperfusion injury via inhibition of apoptosis," American Journal of Chinese Medicine, vol. 45, no. 07, pp. 14211439, 2017.

[42] B. Taferner, W. Schuehly, A. Huefner et al., "Modulation of GABAA-receptors by honokiol and derivatives: Subtype selectivity and structure-activity relationship," Journal of Medicinal Chemistry, vol. 54, no. 15, pp. 5349-5361, 2011.

[43] Y. Sakaue, H. Domon, M. Oda et al., "Anti-biofilm and bactericidal effects of magnolia bark-derived magnolol and honokiol on Streptococcus mutans," Microbiology and Immunology, vol. 60, no. 1, pp. 10-16, 2016.

[44] J. Dong, H. Ding, Y. Liu et al., "Magnolol protects channel catfish from Aeromonas hydrophila infection via inhibiting the expression of aerolysin," Veterinary Microbiology, vol. 211, pp. 119-123, 2017. 
[45] X. Chen, Y. Hu, L. Shan, X. Yu, K. Hao, and G.-X. Wang, "Magnolol and honokiol from Magnolia officinalis enhanced antiviral immune responses against grass carp reovirus in Ctenopharyngodon idella kidney cells," Fish and Shellfish Immunology, vol. 63, pp. 245-254, 2017.

[46] X. Chen, K. Hao, X. Yu et al., "Magnolol protects Ctenopharyngodon idella kidney cells from apoptosis induced by grass carp reovirus," Fish and Shellfish Immunology, vol. 74, pp. 426-435, 2018.

[47] R. Amorati, J. Zotova, A. Baschieri, and L. Valgimigli, "Antioxidant activity of magnolol and honokiol: kinetic and mechanistic investigations of their reaction with peroxyl radicals," The Journal of Organic Chemistry, vol. 80, no. 21, pp. 10651-10659, 2015.

[48] J. Shen, K. Man, P. Huang et al., "Honokiol and magnolol as multifunctional antioxidative molecules for dermatologic disorders," Molecules, vol. 15, no. 9, pp. 6452-6465, 2010.

[49] L. Dong, S. Zhou, X. Yang, Q. Chen, Y. He, and W. Huang, "Magnolol protects against oxidative stress-mediated neural cell damage by modulating mitochondrial dysfunction and PI3K/ Akt signaling," Journal of Molecular Neuroscience, vol. 50, no. 3 , pp. 469-481, 2013.

[50] L.-C. Chen, Y.-C. Liu, Y.-C. Liang, Y.-S. Ho, and W.-S. Lee, "Magnolol inhibits human glioblastoma cell proliferation through upregulation of p21/Cip1," Journal of Agricultural and Food Chemistry, vol. 57, no. 16, pp. 7331-7337, 2009.

[51] L.-C. Chen and W.-S. Lee, "P27/Kipl is responsible for magnolol-induced U373 apoptosis in vitro and in Vivo," Journal of Agricultural and Food Chemistry, vol. 61, no. 11, pp. 2811-2819, 2013.

[52] F. Zhang, H. Ren, J. Shen, X. Zhang, H. Ye, and D. Shen, "Magnolol suppresses the proliferation and invasion of cholangiocarcinoma cells via inhibiting the NF- $\kappa$ B signaling pathway," Biomedicine \& Pharmacotherapy, vol. 94, pp. 474-480, 2017.

[53] M.-C. Chen, Y.-L. Chen, C.-F. Lee, C.-H. Hung, and T.-C. Chou, "Supplementation of magnolol attenuates skeletal muscle atrophy in bladder cancer-bearing mice undergoing chemotherapy via suppression of FoxO3 activation and induction of IGF-1," PLoS ONE, vol. 10, no. 11, Article ID e0143594, 2015.

[54] K. M. Kim, N. S. Kim, J. Kim et al., "Magnolol suppresses vascular endothelial growth factor-induced angiogenesis by inhibiting ras-dependent mitogen-activated protein kinase and phosphatidylinositol 3-kinase/Akt signaling pathways," Nutrition and Cancer, vol. 65, no. 8, pp. 1245-1253, 2013.

[55] Y.-S. Li, Y.-F. Hong, J. He et al., "Effects of magnolol on impairment of learning and memory abilities induced by scopolamine in mice," Biological \& Pharmaceutical Bulletin, vol. 36, no. 5, pp. 764-771, 2013.

[56] Y. Bai, L. Song, G. Dai et al., "Antidepressant effects of magnolol in a mouse model of depression induced by chronic corticosterone injection," Steroids, vol. 135, pp. 73-78, 2018.

[57] X. Liu, X. Chen, Y. Zhu, K. Wang, and Y. Wang, "Effect of magnolol on cerebral injury and blood brain barrier dysfunction induced by ischemia-reperfusion in vivo and in vitro," Metabolic Brain Disease, vol. 32, no. 4, pp. 1109-1118, 2017.

[58] C. Liang, C. Lee, H. Sung et al., "Magnolol reduced TNF$\alpha$-induced vascular cell adhesion molecule-1 expression in endothelial cells via JNK/p38 and NF- $\kappa$ B signaling pathways," American Journal of Chinese Medicine, vol. 42, no. 03, pp. 619637, 2014.
[59] S. S. Choi, B. Y. Cha, Y. S. Lee et al., "Magnolol enhances adipocyte differentiation and glucose uptake in 3T3-L1 cells," Life Sciences, vol. 84, no. 25-26, pp. 908-914, 2009.

[60] S. Liu, Y. Zhou, X. Niu et al., "Magnolol restores the activity of meropenem against NDM-1-producing Escherichia coli by inhibiting the activity of metallo-beta-lactamase," Cell Death Discovery, vol. 4, no. 1, p. 28, 2018.

[61] S. H. Lu, R. Y. Huang, and T. C. Chou, "Magnolol ameliorates ligature-induced periodontitis in rats and osteoclastogenesis: in vivo and in vitro study," Evidence-Based Complementary and Alternative Medicine, vol. 2013, Article ID 634095, 12 pages, 2013.

[62] L. Pulvirenti, V. Muccilli, N. Cardullo, C. Spatafora, and C. Tringali, "Chemoenzymatic synthesis and $\alpha$-glucosidase inhibitory activity of dimeric neolignans inspired by magnolol," Journal of Natural Products, vol. 80, no. 5, pp. 1648-1657, 2017.

[63] T. Onoda, W. Li, T. Sasaki, M. Miyake, K. Higai, and K. Koike, "Identification and evaluation of magnolol and chrysophanol as the principle protein tyrosine phosphatase- $1 \mathrm{~B}$ inhibitory compounds in a Kampo medicine, Masiningan," Journal of Ethnopharmacology, vol. 186, pp. 84-90, 2016.

[64] N. Fakhrudin, A. Ladurner, A. G. Atanasov et al., "Computeraided discovery, validation, and mechanistic characterization of novel neolignan activators of peroxisome proliferator-activated receptor gamma," Molecular Pharmacology, vol. 77, no. 4, pp. 559-566, 2010.

[65] X. Zhang, H. Huang, H. Chang, and X. Jin, "Magnolol reduces bleomycin-induced rodent lung fibrosis," International Journal of Clinical and Experimental Medicine, vol. 8, no. 9, pp. 1545015457, 2015.

[66] V. Bunel, M.-H. Antoine, C. Stévigny, J. Nortier, and P. Duez, "New in vitro insights on a cell death pathway induced by magnolol and honokiol in aristolochic acid tubulotoxicity," Food and Chemical Toxicology, vol. 87, pp. 77-87, 2016.

[67] S.-Y. Lin, J.-D. Liu, H.-C. Chang, S.-D. Yeh, C.-H. Lin, and W.S. Lee, "Magnolol suppresses proliferation of cultured human colon and liver cancer cells by inhibiting DNA synthesis and activating apoptosis," Journal of Cellular Biochemistry, vol. 84, no. 3, pp. 532-544, 2001.

[68] S.-E. Yang, M.-T. Hsieh, T.-H. Tsai, and S.-L. Hsu, "Effector mechanism of magnolol-induced apoptosis in human lung squamous carcinoma CH27 cells," British Journal of Pharmacology, vol. 138, no. 1, pp. 193-201, 2003.

[69] K. Ikeda, Y. Sakai, and H. Nagase, "Inhibitory effect of magnolol on tumour metastasis in mice," Phytotherapy Research, vol. 17, no. 8, pp. 933-937, 2003.

[70] M. Li, F. Zhang, X. Wang et al., "Magnolol inhibits growth of gallbladder cancer cells through the p53 pathway," Cancer Science, vol. 106, no. 10, pp. 1341-1350, 2015.

[71] J.-R. Tsai, I.-W. Chong, Y.-H. Chen et al., "Magnolol induces apoptosis via caspase-independent pathways in non-small cell lung cancer cells," Archives of Pharmacal Research, vol. 37, no. 4, pp. 548-557, 2014.

[72] J. Shen, H. Ma, T. Zhang et al., "Magnolol Inhibits the growth of non-small cell lung cancer via inhibiting microtubule polymerization," Cellular Physiology and Biochemistry, vol. 42, no. 5, pp. 1789-1801, 2017.

[73] Y. Liu, W. Cao, B. Zhang et al., “The natural compound magnolol inhibits invasion and exhibits potential in human breast cancer therapy," Scientific Reports, vol. 3, no. 1, Article ID 3098, 2013.

[74] M.-C. Chen, C.-F. Lee, W.-H. Huang, and T.-C. Chou, "Magnolol suppresses hypoxia-induced angiogenesis via inhibition 
of HIF-1 $\alpha$ /VEGF signaling pathway in human bladder cancer cells," Biochemical Pharmacology, vol. 85, no. 9, pp. 1278-1287, 2013.

[75] G. D. Kim, J. Oh, H.-J. Park, K. Bae, and S. K. Lee, "Magnolol inhibits angiogenesis by regulating ROS-mediated apoptosis and the PI3K/AKT/mTOR signaling pathway in mES/EBderived endothelial-like cells," International Journal of Oncology, vol. 43, no. 2, pp. 600-610, 2013.

[76] T. Nakazawa, T. Yasuda, and K. Ohsawa, "Metabolites of orally administered Magnolia officinalis extract in rats and man and its antidepressant-like effects in mice," Journal of Pharmacy and Pharmacology, vol. 55, no. 11, pp. 1583-1591, 2003.

[77] L.-F. Li, J. Lu, X.-M. Li et al., "Antidepressant-like effect of magnolol on BDNF up-regulation and serotonergic system activity in unpredictable chronic mild stress treated rats," Phytotherapy Research, vol. 26, no. 8, pp. 1189-1194, 2012.

[78] L.-F. Li, J. Yang, S.-P. Ma, and R. Qu, "Magnolol treatment reversed the glial pathology in an unpredictable chronic mild stress-induced rat model of depression," European Journal of Pharmacology, vol. 711, no. 1-3, pp. 42-49, 2013.

[79] N. Matsui, H. Akae, N. Hirashima et al., "Magnolol enhances hippocampal neurogenesis and exerts antidepressant-like effects in olfactory bulbectomized mice," Phytotherapy Research, vol. 30, no. 11, pp. 1856-1861, 2016.

[80] J. Cheng, S. Dong, L. Yi, D. Geng, and Q. Liu, "Magnolol abrogates chronic mild stress-induced depressive-like behaviors by inhibiting neuroinflammation and oxidative stress in the prefrontal cortex of mice," International Immunopharmacology, vol. 59, pp. 61-67, 2018.

[81] D. J. Kim and Y. S. Kim, "Magnolol protects against trimethyltin-induced neuronal damage and glial activation in vitro and in vivo," NeuroToxicology, vol. 53, pp. 173-185, 2016.

[82] D.-Q. Kou, Y.-L. Jiang, J.-H. Qin, and Y.-H. Huang, "Magnolol attenuates the inflammation and apoptosis through the activation of SIRT1 in experimental stroke rats," Pharmacological Reports, vol. 69, no. 4, pp. 642-647, 2017.

[83] C.-C. Wang, K.-C. Lin, B.-S. Lin, C.-C. Chio, and J.-R. Kuo, "Resuscitation from experimental traumatic brain injury by magnolol therapy," Journal of Surgical Research, vol. 184, no. 2, pp. 1045-1052, 2013.

[84] S. Julius, B. M. Egan, N. A. Kaciroti, S. D. Nesbitt, and A. K. Chen, "In prehypertension leukocytosis is associated with body mass index but not with blood pressure or incident hypertension," Journal of Hypertension, vol. 32, no. 2, pp. 251-259, 2014.

[85] L. Wu, H. Zou, W. Xia, Q. Dong, and L. Wang, "Role of magnolol in the proliferation of vascular smooth muscle cells," Herz, vol. 40, no. 3, pp. 542-548, 2015.

[86] R. Karki, S. B. Kim, and D. W. Kim, "Magnolol inhibits migration of vascular smooth muscle cells via cytoskeletal remodeling pathway to attenuate neointima formation," Experimental Cell Research, vol. 319, no. 20, pp. 3238-3250, 2013.

[87] H. Zhang, X. Xu, L. Chen et al., "Molecular determinants of magnolol targeting both RXR $\alpha$ and PPAR $\gamma$," PLoS ONE, vol. 6, no. 11, Article ID e28253, 2011.

[88] N. Xie, C. Hu, A. Guo, H. Liang, P. Du, and G. Yin, "Metabolic regulation of magnolol on the nuclear receptor, liver X receptor," Experimental and Therapeutic Medicine, vol. 9, no. 5, pp. 18271830, 2015.

[89] J.-H. Lee, J. Y. Jung, E. J. Jang et al., "Combination of honokiol and magnolol inhibits hepatic steatosis through AMPK-SREBP1 c pathway," Experimental Biology and Medicine, vol. 240, no. 4, pp. 508-518, 2015.
[90] Y. Tian, H. Feng, L. Han et al., "Magnolol alleviates inflammatory responses and lipid accumulation by AMP-activated protein kinase-dependent peroxisome proliferator-activated receptor $\alpha$ activation," Frontiers in Immunology, vol. 9, p. 147, 2018.

[91] Y.-J. Kim, M.-S. Choi, B. Y. Cha et al., "Long-term supplementation of honokiol and magnolol ameliorates body fat accumulation, insulin resistance, and adipose inflammation in high-fat fed mice," Molecular Nutrition \& Food Research, vol. 57, no. 11, pp. 1988-1998, 2013.

[92] K. S. Suh, S. Chon, W. Jung, and E. M. Choi, "Magnolol protects pancreatic $\beta$-cells against methylglyoxal-induced cellular dysfunction," Chemico-Biological Interactions, vol. 277, pp. 101-109, 2017.

[93] H. Zhai, K. Nakade, Y. Mitsumoto, and Y. Fukuyama, "Honokiol and magnolol induce $\mathrm{Ca} 2+$ mobilization in rat cortical neurons and human neuroblastoma SH-SY5Y cells," European Journal of Pharmacology, vol. 474, no. 2-3, pp. 199-204, 2003.

[94] J.-P. Wang and C.-C. Chen, "Magnolol induces cytosolic-free $\mathrm{Ca} 2+$ elevation in rat neutrophils primarily via inositol trisphosphate signalling pathway," European Journal of Pharmacology, vol. 352, no. 2-3, pp. 329-334, 1998.

[95] S.-F. Hsieh, C.-T. Chou, W.-Z. Liang et al., "The effect of magnolol on $\mathrm{Ca} 2+$ homeostasis and its related physiology in human oral cancer cells," Archives of Oral Biolog, vol. 89, pp. 4954, 2018.

[96] C.-H. Ko, H.-H. Chen, Y.-R. Lin, and M.-H. Chan, "Inhibition of smooth muscle contraction by magnolol and honokiol in porcine trachea," Planta Medica, vol. 69, no. 6, pp. 532-536, 2003.

[97] Y.-C. Lu, H.-H. Chen, C.-H. Ko, Y.-R. Lin, and M.-H. Chan, "The mechanism of honokiol-induced and magnolol-induced inhibition on muscle contraction and $\mathrm{Ca} 2+$ mobilization in rat uterus," Naunyn-Schmiedeberg's Archives of Pharmacology, vol. 368, no. 4, pp. 262-269, 2003.

[98] M. Zhang, K.-H. Zang, J.-L. Luo et al., "Magnolol inhibits colonic motility through down-regulation of voltage-sensitive L-type Ca2+ channels of colonic smooth muscle cells in rats," Phytomedicine, vol. 20, no. 14, pp. 1272-1279, 2013.

[99] Z. X. Bian, G. S. Zhang, K. L. Wong et al., "Inhibitory effects of magnolol on distal colon of guinea pig in vitro," Biological \& Pharmaceutical Bulletin, vol. 29, no. 4, pp. 790-795, 2006.

[100] Y. Deng, X. Han, S. Tang et al., "Magnolol and honokiol regulate the calcium-activated potassium channels signaling pathway in Enterotoxigenic Escherichia coli-induced diarrhea mice," European Journal of Pharmacology, vol. 755, pp. 66-73, 2015.

[101] S. Y. Kim, J. Kim, S. I. Jeong, K. Y. Jahng, and K. Y. Yu, "Antimicrobial effects and resistant regulation of magnolol and honokiol on methicillin-resistant staphylococcus aureus," BioMed Research International, vol. 2015, Article ID 283630, 2015.

[102] E.-J. Choi, H.-I. Kim, J.-A. Kim et al., “The herbal-derived honokiol and magnolol enhances immune response to infection with methicillin-sensitive Staphylococcus aureus (MSSA) and methicillin-resistant S. aureus (MRSA)," Applied Microbiology and Biotechnology, vol. 99, no. 10, pp. 4387-4396, 2015.

[103] G. Zuo, X. Zhang, J. Han, Y. Li, and G. Wang, "In vitro synergism of magnolol and honokiol in combination with antibacterial agents against clinical isolates of methicillin-resistant Staphylococcus aureus (MRSA)," BMC Complementary and Alternative Medicine, vol. 15, no. 1, p. 425, 2015. 
[104] L. Sun, K. Liao, and D. Wang, "Effects of magnolol and honokiol on adhesion, yeast-hyphal transition, and formation of biofilm by candida albicans," PLOS ONE, vol. 10, no. 2, Article ID e0117695, 2015.

[105] P. Zhou, J. Fu, H. Hua, and X. Liu, "In vitro inhibitory activities of magnolol against Candida spp," Drug Design, Development and Therapy, vol. 11, pp. 2653-2661, 2017.

[106] L.-M. Sun, K. Liao, S. Liang, P.-H. Yu, and D.-Y. Wang, "Synergistic activity of magnolol with azoles and its possible antifungal mechanism against Candida albicans," Journal of Applied Microbiology, vol. 118, no. 4, pp. 826-838, 2015.

[107] J. Behbehani, S. Shreaz, M. Irshad, and M. Karched, "The natural compound magnolol affects growth, biofilm formation, and ultrastructure of oral Candida isolates," Microbial Pathogenesis, vol. 113, pp. 209-217, 2017.

[108] H. Safiaghdam, V. Oveissi, R. Bahramsoltani, M. H. Farzaei, and R. Rahimi, "Medicinal plants for gingivitis: A review of clinical trials," Iranian Journal of Basic Medical Sciences, vol. 21, no. 10, pp. 978-991, 2018.

[109] G. Campus, M. G. Cagetti, F. Cocco et al., "Effect of a sugarfree chewing gum containing magnolia bark extract on different variables related to caries and gingivitis: A randomized controlled intervention trial," Caries Research, vol. 45, no. 4, pp. 393-399, 2011.

[110] S.-H. Lu, T.-H. Chen, and T.-C. Chou, "Magnolol inhibits RANKL-induced osteoclast differentiation of RAW 264.7 macrophages through heme oxygenase-1-dependent inhibition of NFATcl expression," Journal of Natural Products, vol. 78, no. 1, pp. 61-68, 2015.

[111] H. Kuk, C. Arnold, R. Meyer, M. Hecker, and T. Korff, "Magnolol inhibits venous remodeling in mice," Scientific Reports, vol. 7, no. 1, p. 17820, 2017.

[112] H. Zhang, B. Ju, X. Zhang et al., "Magnolol attenuates concanavalin a-induced hepatic fibrosis, inhibits CD4+ T helper 17 (Th17) cell differentiation and suppresses hepatic stellate cell activation: blockade of Smad3/Smad4 signalling," Basic \& Clinical Pharmacology \& Toxicology, vol. 120, no. 6, pp. 560-570, 2017.

[113] C. Mei, S. He, P. Yin et al., "Magnolol pretreatment attenuates heat stress-induced IEC-6 cell injury," Journal of Zhejiang University Science B, vol. 17, no. 6, pp. 413-424, 2016.

[114] A.-R. Im, J. H. Song, M. Y. Lee, and S. Chae, "Magnolol reduces UVB-induced photodamage by regulating matrix metalloproteinase activity," Environmental Toxicology and Pharmacology, vol. 39, no. 1, pp. 417-423, 2015.

[115] X. Wang, T. Wang, C. Zhang, F. Liu, and C.-M. Fu, "Study on influence of Magnolia officinalis before and after "sweating" on gastrointestinal motility disorder in rats by metabolomics," China Journal of Chinese Materia Medica, vol. 44, no. 6, pp. 1170-1178, 2019.

[116] X. Wang, C. Zhang, M. Zheng, F. Gao, J. Zhang, and F. Liu, "Metabolomics analysis of L-arginine induced gastrointestinal motility disorder in rats using UPLC-MS after magnolol treatment," Frontiers in Pharmacology, vol. 10, p. 183, 2019.

[117] Y. Deng, X. Han, S. Tang, C. Li, W. Xiao, and Z. Tan, "Magnolol and honokiol attenuate apoptosis of enterotoxigenic escherichia coli-induced intestinal epithelium by maintaining secretion and absorption homeostasis and protecting mucosal integrity," Medical Science Monitor, vol. 24, pp. 3348-3356, 2018.

[118] N. Li, Y. Song, W. Zhang et al., "Evaluation of the in vitro and in vivo genotoxicity of magnolia bark extract," Regulatory Toxicology and Pharmacology, vol. 49, no. 3, pp. 154-159, 2007.
[119] L. E. Fried and J. L. Arbiser, "Honokiol, a multifunctional antiangiogenic and antitumor agent," Antioxidants \& Redox Signaling, vol. 11, no. 5, pp. 1139-1148, 2009.

[120] Z. Liu, X. Zhang, W. Cui et al., "Evaluation of short-term and subchronic toxicity of magnolia bark extract in rats," Regulatory Toxicology and Pharmacology, vol. 49, no. 3, pp. 160-171, 2007.

[121] F. Schifano, V. Guarino, D. G. Papanti, J. Baccarin, L. Orsolini, and J. M. Corkery, "Is there a potential of misuse for Magnolia officinalis compounds/metabolites?" Journal of Psychopharmacology, vol. 32, no. 3, 2017. 

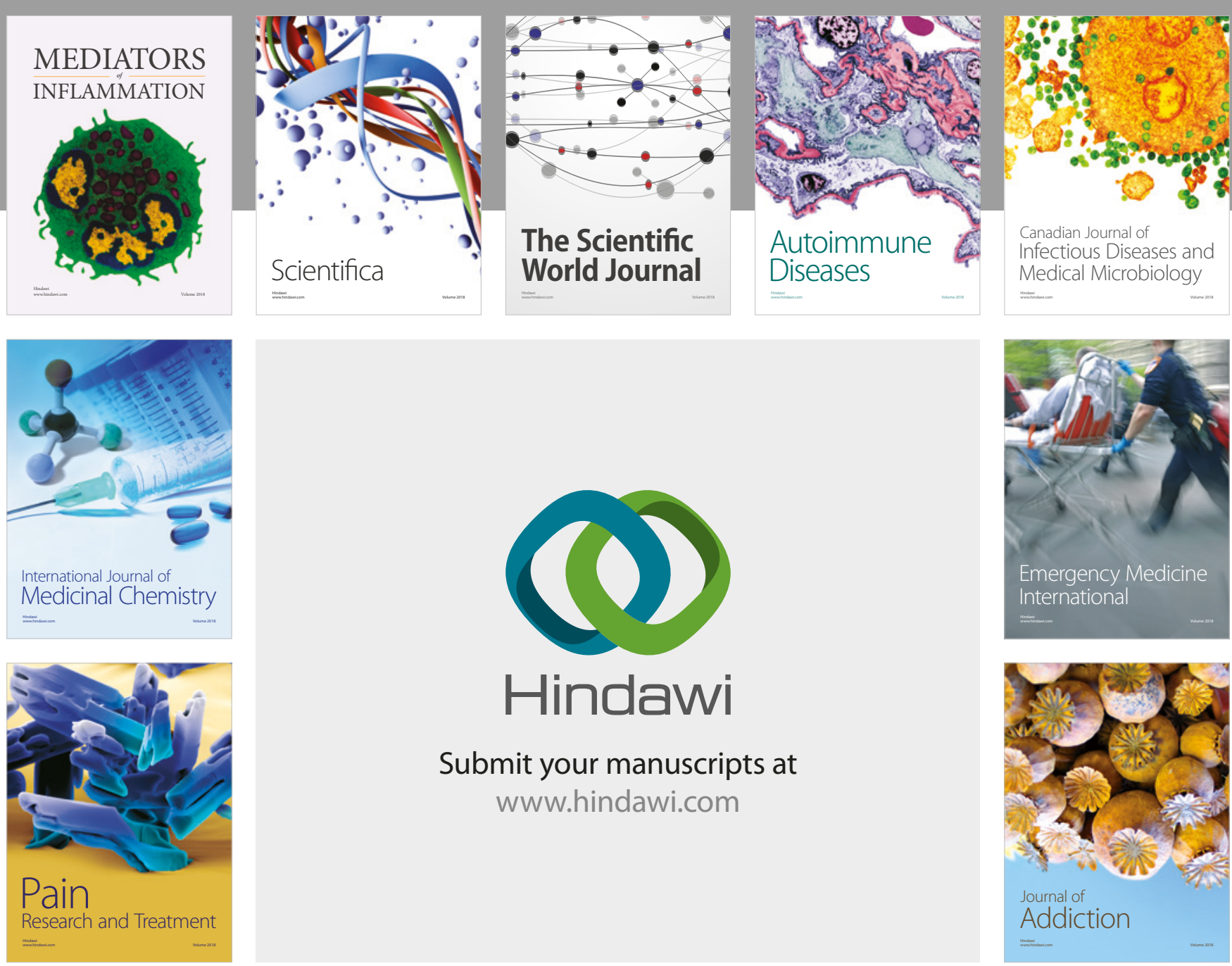

Canadian Journal of
Infectious Diseases and Medical Microbiology

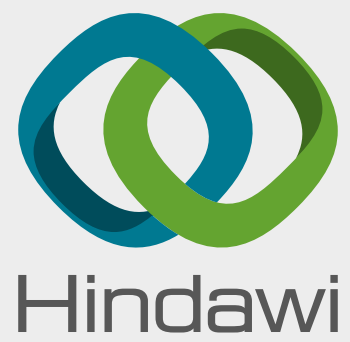

Submit your manuscripts at

www.hindawi.com
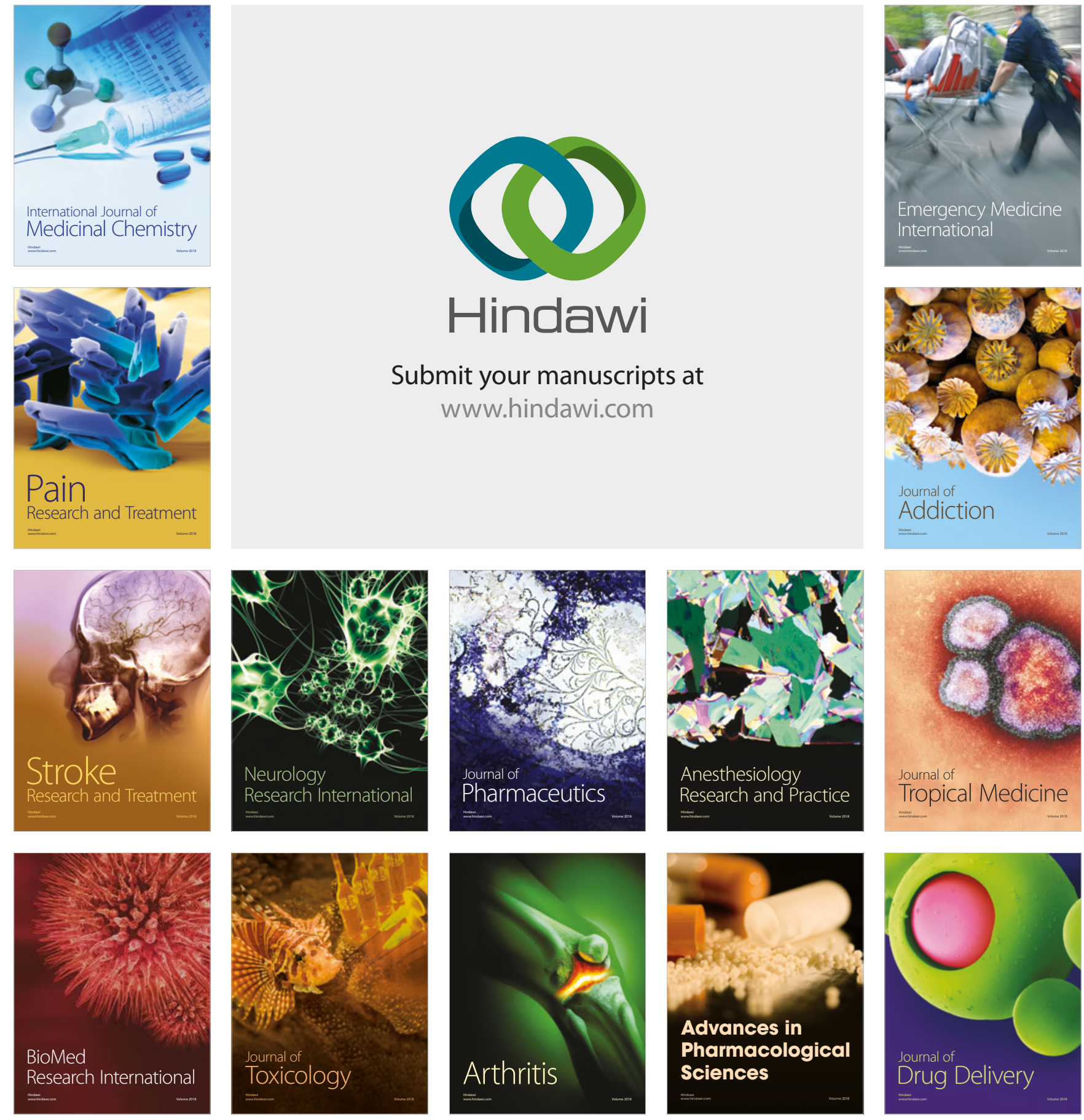